Original Research Paper

\title{
Observational Study of Wind Shear in Northeastern Brazil
}

\author{
${ }^{1}$ Fernando R. Martins, ${ }^{2}$ André R. Gonçalves and ${ }^{2}$ Enio B. Pereira \\ ${ }^{I}$ Department for Sea Science, Federal University of São Paulo, \\ Campus Baixada Santista (UNIFESP), Santos, SP, Brazil \\ ${ }^{2}$ Centre for Earth System Science, \\ Brazilian Institute for Space Research (CCST/INPE), São José dos Campos, SP, Brazil
}

Article history

Received: 10-02-2016

Revised: 10-3-2016

Accepted: 11-3-2016

Corresponding Author:

Fernando R. Martins

Department for Sea Science,

Federal University of São Paulo,

Campus Baixada Santista

(UNIFESP), Santos, SP, Brazil

Email:Fernando.martins@unifesp.br

\begin{abstract}
The wind energy share is growing fast in Brazil and a better understanding of wind speed vertical profiles is essential for accurate power density estimates. The wind shear is highly variable in space and time, being influenced by surface layer stability. Studies concerning wind vertical profiles may have a significant contribution to the Brazilian energy sector. However, wind observational data are very scarce and most of them were acquired in automated weather stations. This work investigates the wind vertical profile data acquired at a wind mast in a semi-arid region of Brazilian Northeastern region, correlating it to stability conditions of the surface boundary layer, surface roughness and friction velocity. The results indicated that strong winds $\left(>7 \mathrm{~m} \mathrm{sec}^{-1}\right)$ overcome the stability effects, allowing a better estimate of roughness length, friction velocity and exponential coefficient. In a second step, the wind speed at $50 \mathrm{~m}$ agl. Were estimated from wind measurements at $25 \mathrm{~m}$ agl. The wind estimates were compared to observations, showing that exponential and logarithmic approaches were able to simulate wind profile. The exponential approach presented the lowest BIAS for rainy season, but overestimated high wind velocities. Finally, a sensitivity analysis demonstrated how uncertainties on roughness length and exponential coefficient impacts on BIAS deviation and reduce the confidence on wind power density estimates. The results demonstrated the importance in understanding how wind vertical profile is related to atmospheric stability condition in order to get reliable values for the shear parameters from mast observations. It is still more critical if wind database is short-term and when dealing with lower wind speeds.
\end{abstract}

Keywords: Atmospheric Boundary Layer, Wind Shear, Experimental Data, Wind Energy

\section{Introduction}

The installed wind power capacity is increasing worldwide along the last years, but several technological and economical challenges still must be overcome in order to promote the integration of wind resource on the energy matrix of emerging countries like Brazil (Boute, 2012). The wind energy started to be an economical alternative for electricity generation in Brazil after 2002, with the deployment of the Brazilian incentive program for renewable energies, named PROINFA, which supported several wind energy projects along the last decade, mainly in the Northeastern region. The wind power plants already endorsed to operate will attain around 5\% share on the electricity matrix in a short timeframe (Martins and Pereira, 2011; Pereira et al., 2012).

Due to the fact that wind energy is highly unsteady in space and time, one of the key challenges imposed to energy sector consists in predicting wind variability in order to optimize the electricity system generation and wind farms operation. Information on the wind speed at the hub height plays an essential role in the overall performance assessment of wind farms.

As a consequence, long data series of climate and meteorological variables plays an essential role in wind power plants design and in the overall performance assessment of wind farms. However, the low availability of free access database and the expensive budget for implementation and operation of 
meteorological masts has been pointed out as a barrier to increase the wind energy deployment in Brazil (Martins and Pereira, 2011).

Efforts in research on numerical modeling together with remote sensing of atmosphere are being developed in order to overcome this barrier and provide reliable data to meet the information demand of the energy sector. Numerical Weather Prediction models (NWP) can contribute by simulating the dynamical processes in atmosphere in order to estimate and forecast wind power in several temporal and spatial scales (Stathopoulos et al., 2013; Carvalho et al., 2012; Wang et al., 2011). Nevertheless, the wind data acquisition are essential to evaluate deviations in wind speed estimates as such deviations have great impact on wind power density due to the cubic power factor, as presented in the Equation 1:

$$
D_{p}=\frac{1}{2} \rho U^{3}
$$

where, $D_{p}$ stands for the wind power density, $\rho$ is the air density and $U$ is the wind velocity.

Bearing this scenario in mind, studies concerning wind vertical profiles have a significant contribution to reduce the snags caused by lack of observed wind data acquired at compatible height of the modern wind turbines (Bañuelos-Ruedas et al., 2010; Bunse and Mellinghoff, 2008). The purpose of this work was to analyze the variability of observed wind vertical profiles for a wind tower in a semi-arid region at Northeastern region of Brazil, linking it to the surface roughness and the atmospheric stability conditions at the surface boundary layer. Statistical analyses were done for rainy and dry seasons in order to evaluate how climate seasonal variability changes the wind vertical profile. Understanding how wind vertical profile varies as consequence of climate variability and atmospheric conditions is important to improve the wind resource assessment and to provide useful information as input for statistical methods used to correct the wind forecast such as Kalman filter (Sharan and Kumar, 2010; Alafouzos et al., 2006).

The methodology presented in this study can also be used to fill gaps in wind database caused by acquisition problems or electronic failures in meteorological masts. It is usual to take some time to identify and fix such errors and problems in the acquisition system, mainly in remote areas where the cost and time to maintenance is high. The results have demonstrated that the wind velocity measured at one height can be used to estimate wind speed at any other height provided the roughness length and friction velocity are estimated correctly and accounting for climate variability and atmospheric stability conditions.

\section{Numerical Approaches for Vertical Wind Profile}

The mesoscale atmospheric circulation and changes in surface heat fluxes modify the wind vertical profiles. The Atmospheric Boundary Layer (ABL) comprises the lower portion of the atmosphere susceptible to surface effects in a one-hour timeframe, according to Stull (1988). The ABL encompass a thinner layer characterized by high vertical gradients of momentum, humidity and temperature called Surface Boundary Layer (SBL). Lower wind velocities are observed in SBL due to the large influence of the surface roughness and obstacles on the vertical fluxes and local atmospheric movements.

The parameterization of physical processes in $\mathrm{ABL}$ is a key point to get reliable wind speed estimates at the hub height from NWP models. The scientific literature presents several approaches to evaluate the vertical wind profile (Bañuelos-Ruedas et al., 2010; Sharan and Kumar, 2010). The most used approaches in NWP models are the logarithmic law, shown in Equation 2 and the exponential fitting, described in Equation 3:

$$
\begin{aligned}
& U(z)=\frac{u^{*}}{k} \ln \left(\frac{z}{z_{0}}\right) \\
& \frac{U\left(z_{r}\right)}{U(z)}=\left(\frac{z_{r}}{z}\right)^{a}
\end{aligned}
$$

where, $u^{*}$ stands for the friction velocity, $k$ represents the Von Karman constant $(k=0,4)$ and $\alpha$ is the power factor. The variables $Z_{r}$ and $Z$ are the altitudes at the reference level and at the level of interest for evaluating the wind speed, respectively. The roughness length, $Z_{0}$, is a measure of the turbulence induced by the surface obstacles and it is related to momentum absorption by them. It is proportional but generally lower than the height of the roughness elements and should not be affected by wind velocity (Stull, 1988).

The numeric approach commonly used in NWP models adopts the stability corrections based on the similarity theory as described by Monin and Obukhov (1954). The Monin-Obhukov theory is an approach to estimate the vertical profiles of momentum and temperature using data of surface heat fluxes. However, it can provide wind estimates with large deviations according to Foken (2006) when dealing with high surface roughness. Other studies have evaluated and discussed the behavior of Monin-Obukhov similarity in ABL. Pahlow at al. (2001) concluded that the applicability of Monin-Obukhov similarity theory under stable atmospheric conditions is not valid in general. McNaughton (2009) also discussed the anomalies of Monin-Obukhov theory and proposed a new scheme to describe turbulence, wind and temperature profiles. 
However, his new proposed scheme has some limitations and the vertical flow cannot be described in terms of experimental parameters measured at just one point. In general for wind resource assessment and forecast, it is required to correct the NWP outputs using model output statistics approaches based on local wind data acquired in wind masts or Automated Weather Stations (AWS).

\section{Observational Data}

For this work, wind data was acquired in a wind measurement mast located at a rural area of São João do Cariri (SJC), a small city in a semi-arid area of Brazilian Northeastern region $\left(07^{\circ} 22^{\prime} 54^{\prime \prime} \mathrm{S}, 36^{\circ} 31^{\prime}\right.$ $\left.38^{\prime \prime} \mathrm{W}\right)$. The mast is placed at $718 \mathrm{~m}$ above the sea level in the Borborema plateau and it is surrounded by the local typical land cover: Dry vegetation composed by grass and small shrubs, called 'Caatinga'. The rainy season is concentrated between April and July and the mean annual precipitation is around $400 \mathrm{~mm} /$ year.
Although annual precipitation is very low, the local cloudiness is above $5 / 10$ throughout the year reducing the mean insolation to values between 2.000 and 2.900 $\mathrm{h} /$ year. November and December are the hottest months of the year presenting average temperatures close to $25^{\circ} \mathrm{C}$. The lowest temperatures occur in July, around $21^{\circ} \mathrm{C}$ (Araujo, 2005; INMET 2016).

Figure 1 presents a location map and some pictures of the measurement site. The wind mast has anemometers, wind direction and air temperature sensors in two height levels: 25 and $50 \mathrm{~m}$. The database provides $10 \mathrm{~min}$ average for air temperature, wind speed and direction. Data acquired during the dry (October and November) and the rainy months (April and May) of 2006 were used. The data quality control was accomplished according to World Meteorological Organization requirements. More details in measurement site setup and data quality control are available at http://sonda.ccst.inpe.br/.

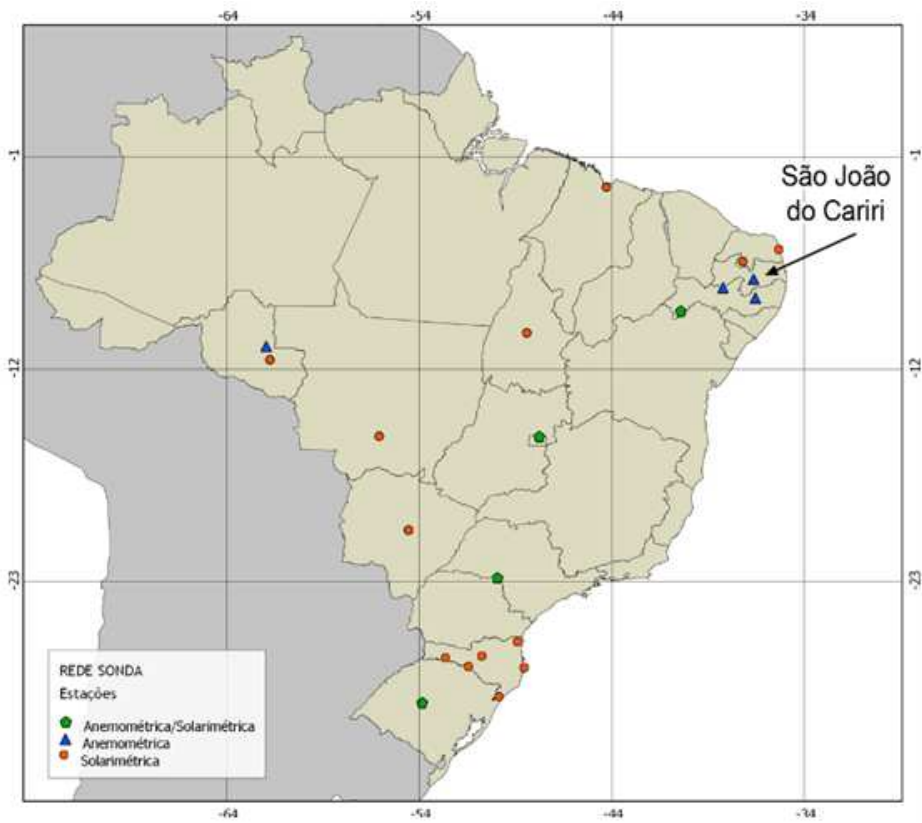

(a)

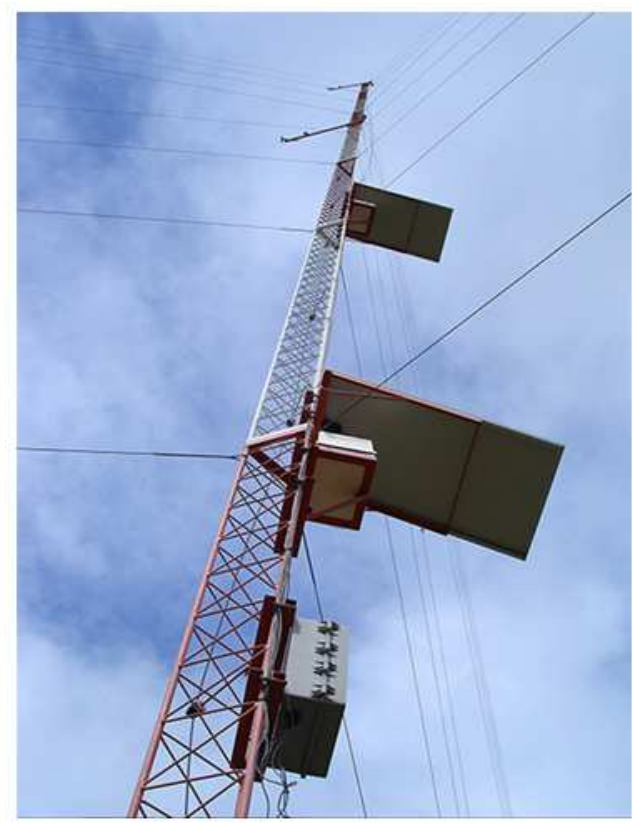

(b)

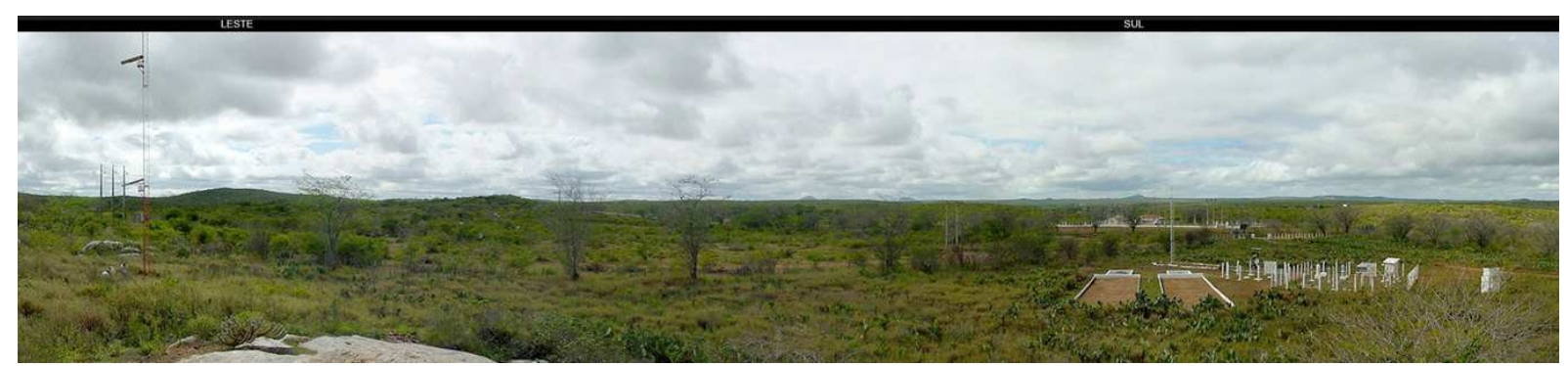

(c)

Fig. 1. (a) Location map of the measurement site at São João do Cariri in Northeastern region of Brazil; (b) pictures from the mast and anemometers; and (c) panoramic view of the SE quadrant from the meteorological mast. Source: SONDA project http://sonda.ccst.inpe.br 


\section{Methodology}

This works aims at understanding how the ABL stability conditions and wind speeds are related to the observed wind vertical profiles acquired in Brazilian Semi-arid region. First of all, the wind speed distribution and wind direction frequency were investigated for both seasons in order to understand how the typical climate conditions modify the local atmosphere circulation.

The values for the shear parameters were estimated by fitting the logarithm and exponential functions described in Equations 2 and 3 for each 10 min wind data acquired at the 25 and $50 \mathrm{~m}$ above the ground. The roughness length, $Z_{0}$, was empirically estimated as a function of wind speed and wind direction. Data corresponding to conditions presenting low wind speed or highly stratified layers was discarded and not used to estimate the roughness length. The discarded data could not fit satisfactorily to the Monin-Obukhov theoretical equations as demonstrated by Foken (2006). The BulkRichardson Number, $B R i$, as formulated by Golder (1972), was used to describe the stability condition of the atmosphere for each 10 min observational data:

$$
B R i=\left(\frac{g}{T}\right)\left\lfloor\frac{(\partial \theta / \partial z)}{U^{2}}\right\rfloor z^{-2}
$$

where, $\theta$ is the potential temperature, $g$ stands for the gravity acceleration and $T$ is the air temperature.

In order to investigate the influence of atmospheric stability conditions and the flow patterns, the data analysis was accomplished separately for diurnal and nocturnal times.

Based on these previous data analysis, an extrapolation procedure for vertical wind profile was established for dry and rainy seasons. Wind data acquired at $25 \mathrm{~m}$ above the ground throughout April (rainy) and November (dry) was used to develop the empirical relationship to estimate the wind at $50 \mathrm{~m}$

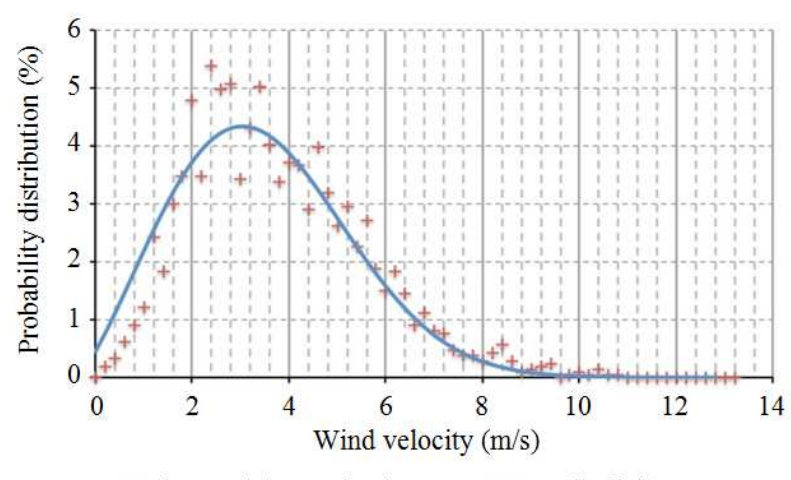

+ Observed data at daytime $\quad$ - Weibull dist.

(a) above the ground. Wind data acquired in May and October was used to validate the empirical extrapolation models for both climate seasons. The deviations on wind intensity and power density estimates were calculated.

\section{Results and Discussion}

\section{Analysis of Wind Data Acquired at SJC}

Figure 2 and 3 show the frequency distribution plots for wind velocity acquired in April (rainy season) and November (dry season) of 2006 at 25 and $50 \mathrm{~m}$ above ground level (agl.), respectively. The blue lines are the Weibull distribution obtained by using the Least Squares Fitting method. The analysis was prepared for two different timeframes-daytime and nighttime hours- in order to investigate the influence of stability conditions in wind velocity distribution. Table 1 presents the Weibull parameters obtained for observed data in each typical climate season.

Figure 2 and 3 demonstrate that wind frequency distributions were not similar for rainy and dry seasons. The wind was more intense along the dry season (November) when the mean wind speed was around 6.5 $\mathrm{m} \mathrm{sec}^{-1}$ at $50 \mathrm{~m}$ height at daytime and night periods. In April (rainy season), the mean wind speed was $4.3 \mathrm{~m}$ $\mathrm{sec}^{-1}$ along the daytime and $3.7 \mathrm{~m} \mathrm{sec}^{-1}$ at night hours. An interesting point is that the variance was larger during night hours in dry season, but it was larger during daytime along the rainy season.

Figure 4 presents the wind direction distribution at $50 \mathrm{~m}$ agl. The wind direction distributions were very similar for rainy and dry season, as well as for diurnal and nocturnal observations. Most of the time, the wind direction was toward South-Southeast direction. The wind blowing toward any other direction than S-SE presented very low speed values. The wind direction distribution showed great persistence due to trade winds influence: Above $90 \%$ in November (dry season) and above $66 \%$ in April. The wind direction distribution observed at $25 \mathrm{~m}$ height was quite similar and it is not presented here.

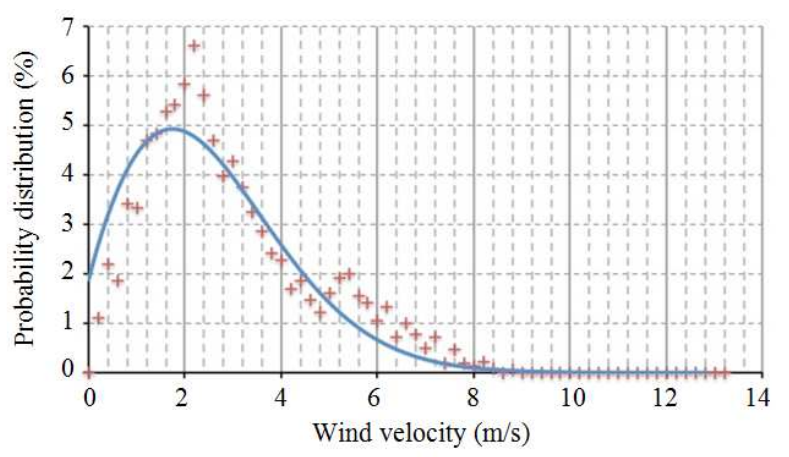

+ Observed data at night $\quad-$ Weibull dist. 


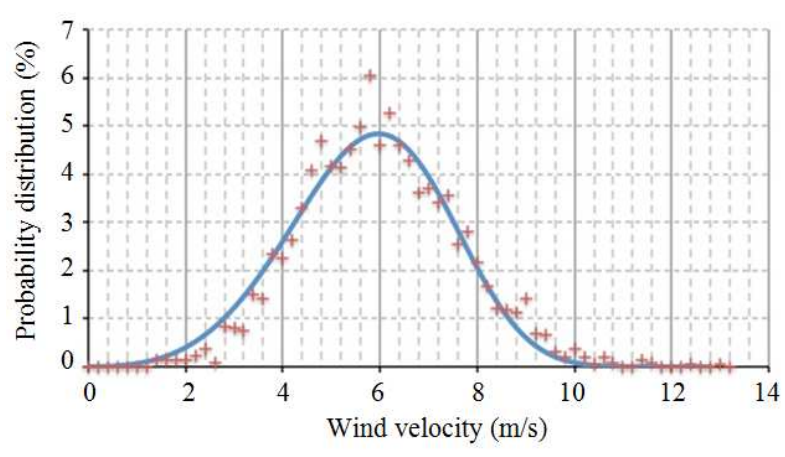

+ Observed data at daytime $\quad$ - Weibull dist.

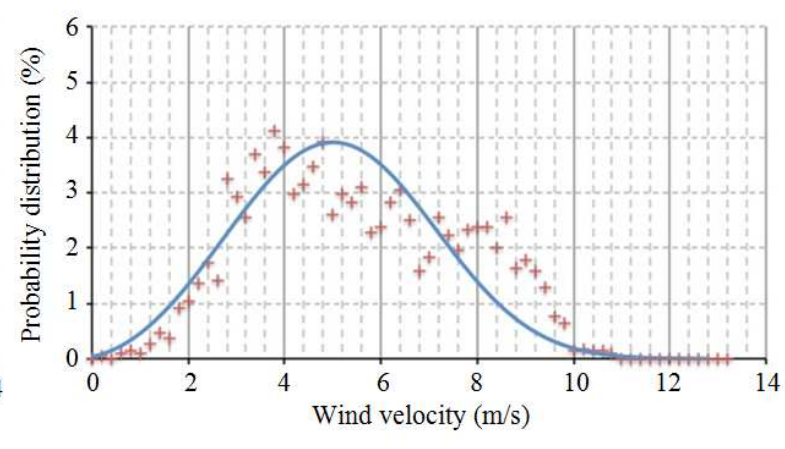

+ Observed data at night $\quad$ - Weibull dist.

(b)

Fig. 2. Wind frequency distributions of data acquired at $25 \mathrm{~m}$ agl. at São João do Cariri in Brazilian Northeastern region. Blue line represents the Weibull distribution fitted to the observation data. Data acquired in April (a) and November/2006 (b)

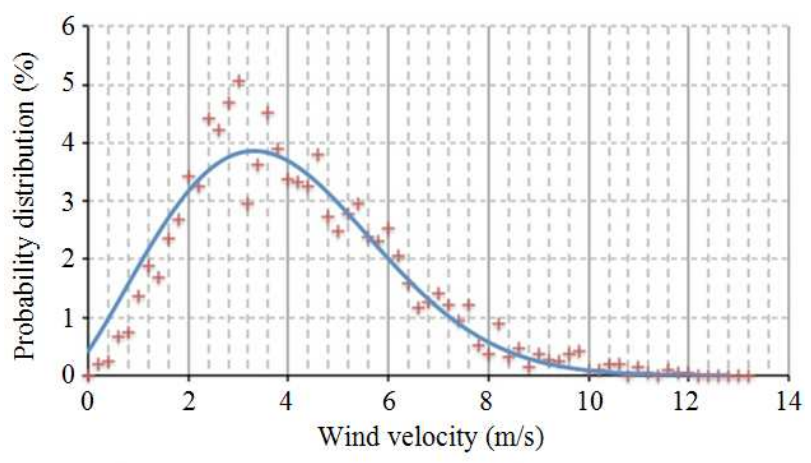

+ Observed data at daytime $\quad$ - Weibull dist.

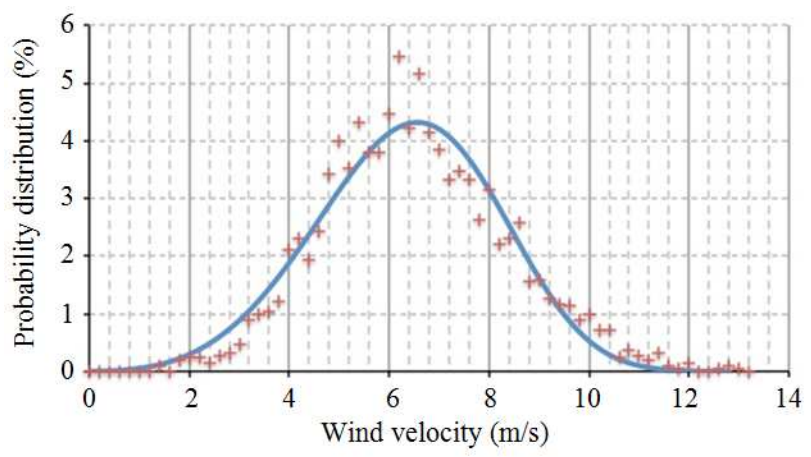

+ Observed data at daytime $\quad-\quad$ Weibull dist.

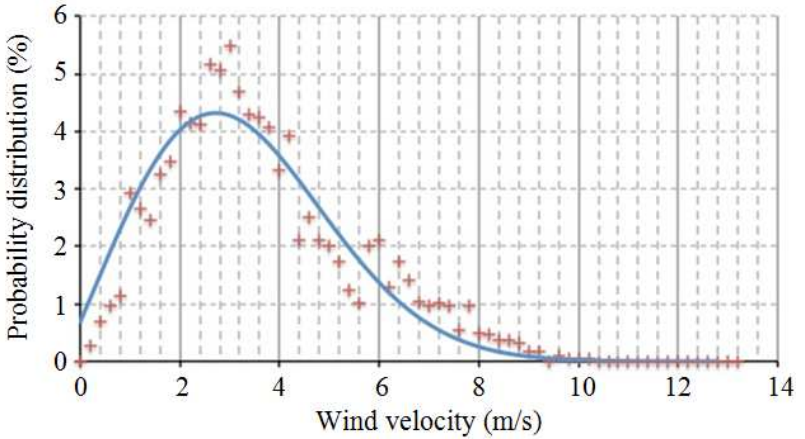

+ Observed data at night $\quad$ - Weibull dist.

(a)

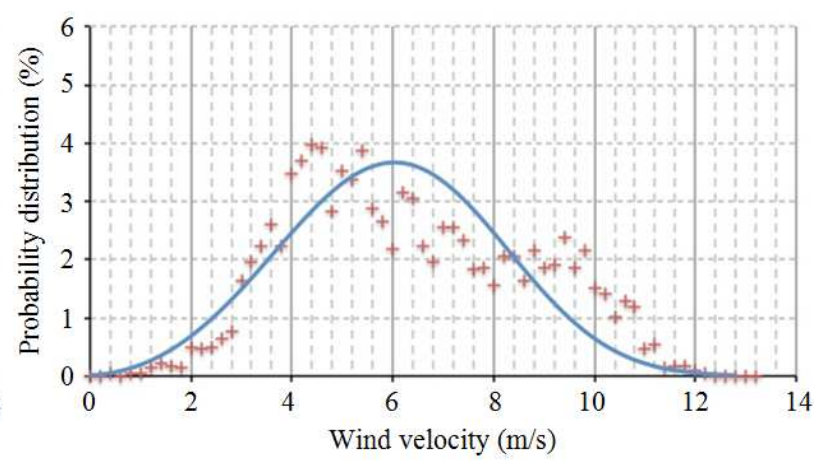

(b)

Fig. 3. Wind frequency distributions of data acquired at $50 \mathrm{~m}$ agl. at São João do Cariri: Brazilian Northeastern region. Blue line represents the Weibull distribution fitted to the observation data. Data acquired in April (a) and November/2006 (b)

Figure 5a shows the scatter-plots of Bulk Richardson number (BRi) as a function of wind velocity acquired at $50 \mathrm{~m}$ height in April and November 2006. It can be noticed that the largest spreading of BRi data occurred when wind velocity was lower than $6 \mathrm{~m} \mathrm{sec}^{-1}$. The data spreading was larger in April than November due to the lower wind speeds and the vertical transport associated to typical convection systems and precipitation events along the rainy season.
Negative values of Bulk-Richardson number indicate the convective instability condition in ABL. The Fig. 5b shows that most of the convective conditions occurred during daytime, both in the rainy and dry seasons. As expected, the convective instability was much more frequent and intense in April (rainy) than in November. Stable conditions were often observed at nocturnal hours and it is indicated by BRi values greater than 0.25 . The neutral atmospheric condition due to large mechanical 
turbulence is indicated by BRi values between 0 and 0.25

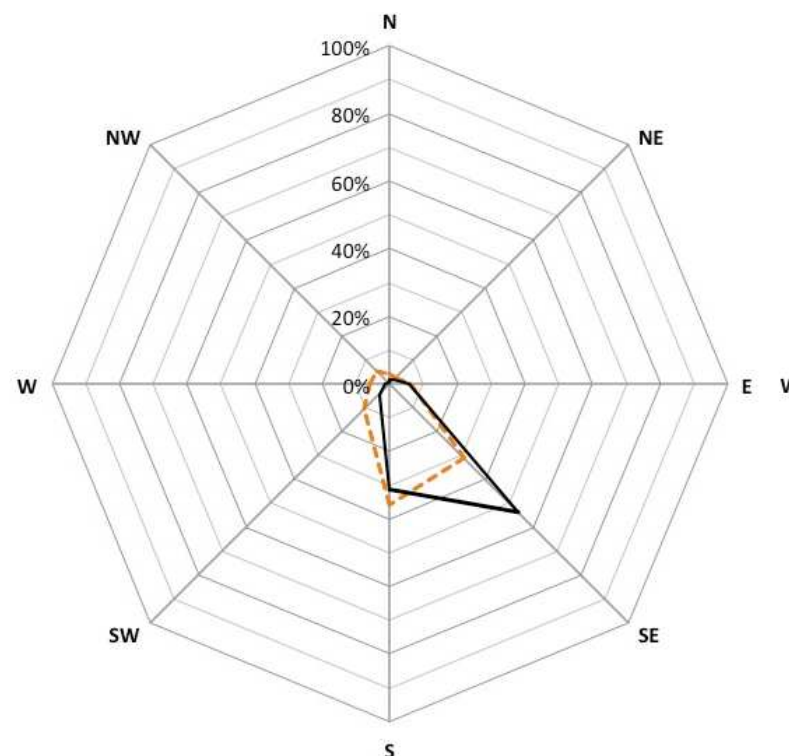

and it was obseved for wind velocities larger than $6 \mathrm{~m} \mathrm{sec}^{-1}$.

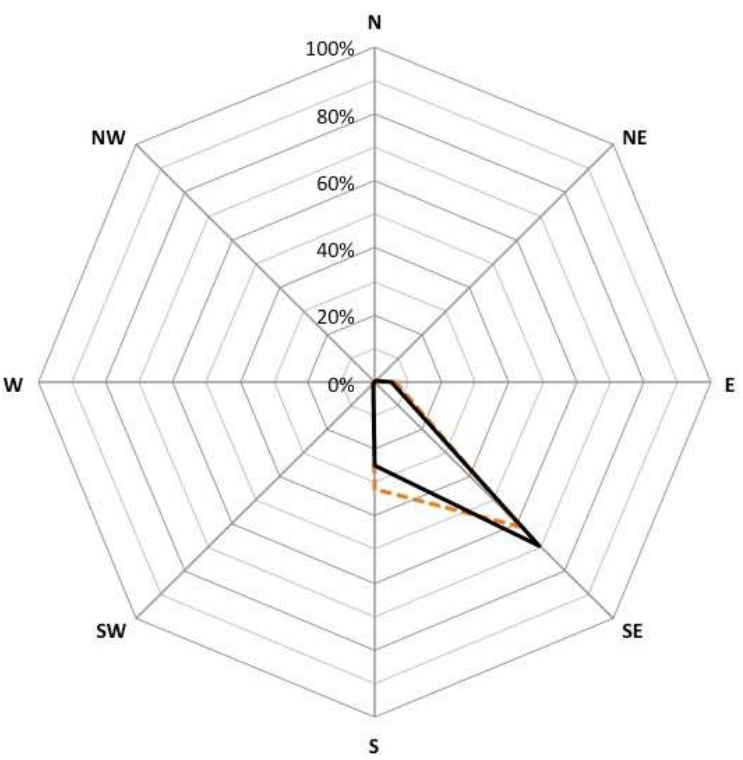

Fig. 4. Statistical distribution of wind direction observed at São João do Cariri: April (left) and November (right). The dashed line represents the diurnal wind data and solid line represents the nocturnal wind data
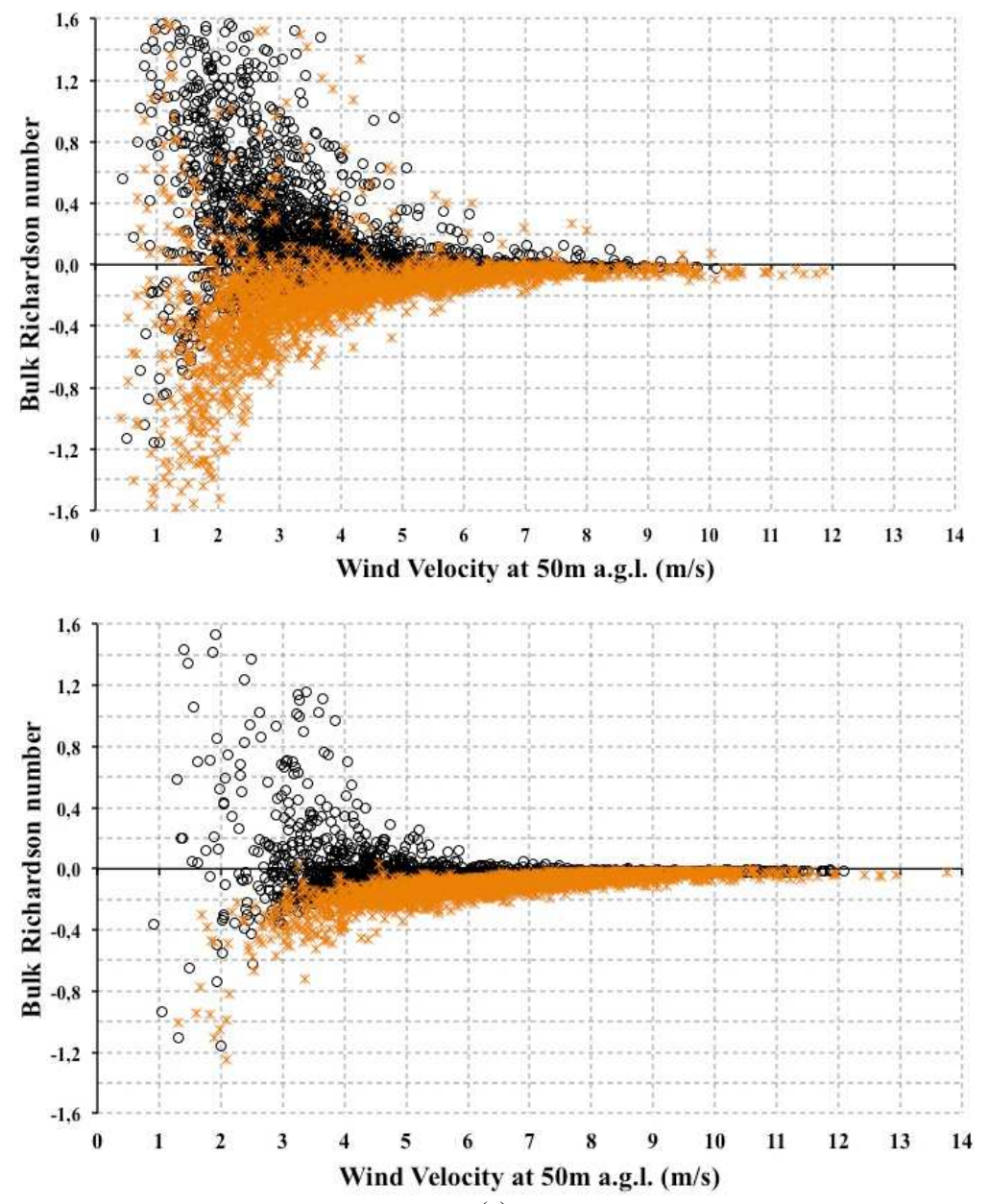

(a) 

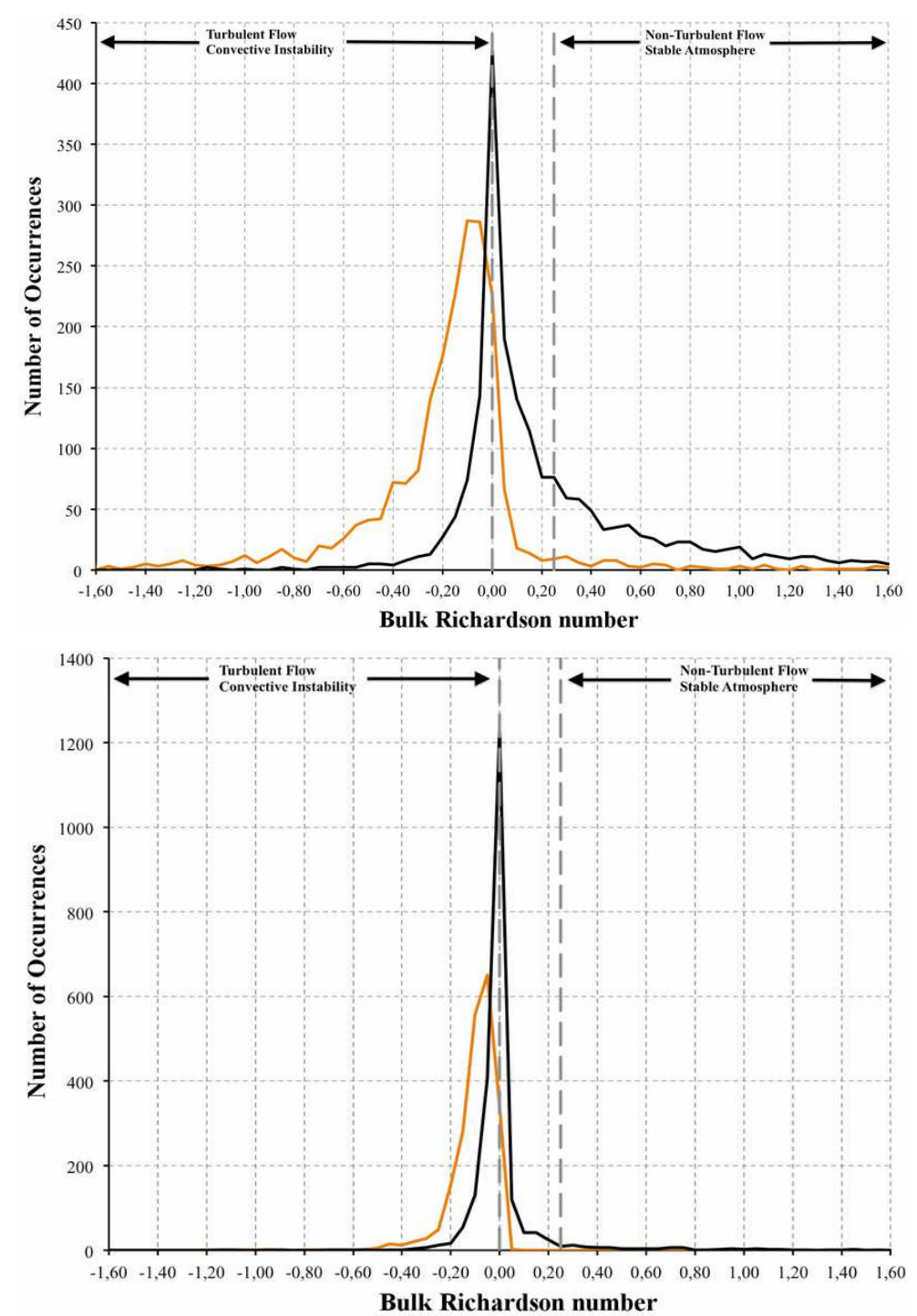

(b)

Fig. 5. (a) Scatter-plot of BRi number versus wind speed at $50 \mathrm{~m}$ agl. for April (left) and November (right) of 2006. (b) Frequency distribution of BRi values in April (left) and November (right). The orange lines were used for diurnal data and black for nocturnal data

Table 1. The Weibull parameters and statistical moments for wind data acquired at São João do Cariri

\begin{tabular}{|c|c|c|c|c|c|c|}
\hline \multirow[b]{2}{*}{ Time period } & \multirow[b]{2}{*}{ Height } & \multicolumn{2}{|c|}{ Weibull distribution parameters } & \multicolumn{3}{|c|}{ Wind speed } \\
\hline & & Shape (k) & Scale (A) & Mean & Median & Variance \\
\hline April - & $25 \mathrm{~m}$ & 2.32 & 4.39 & 3.89 & 3.75 & 3.16 \\
\hline Diurnal observations & $50 \mathrm{~m}$ & 2.25 & 4.82 & 4.27 & 4.10 & 4.04 \\
\hline April - & $25 \mathrm{~m}$ & 1.83 & 3.29 & 2.92 & 2.69 & 2.74 \\
\hline Nocturnal observations & $50 \mathrm{~m}$ & 2.15 & 4.17 & 3.69 & 3.52 & 3.27 \\
\hline November - & $25 \mathrm{~m}$ & 4.33 & 6.77 & 6.16 & 6.22 & 2.59 \\
\hline Diurnal observations & $50 \mathrm{~m}$ & 4.23 & 7.42 & 6.75 & 6.81 & 3.24 \\
\hline November - & $25 \mathrm{~m}$ & 3.08 & 6.14 & 5.49 & 5.45 & 3.80 \\
\hline Nocturnal observations & $50 \mathrm{~m}$ & 3.39 & 7.13 & 6.41 & 6.40 & 4.35 \\
\hline
\end{tabular}

\section{Determination of Roughness Length}

The roughness length values were calculated from Equation 2 for wind data acquired at 25 and $50 \mathrm{~m}$ agl.
The roughness length showed large spreading when plotted against wind velocity or stability parameters, as shown in Fig. 6. As mentioned by Foken (2006) and Pahlow et al. (2001), it was observed that too stable 
conditions or low speed winds cause an inadequate adjustment of the vertical wind profiles. The spreading is reduced if data related to low wind speeds and stable atmospheric conditions are discarded.

The Fig. 7 presents the frequency distribution of roughness length values for April and November taking into account only data with wind speed higher than $6 \mathrm{~m}$ $\mathrm{sec}^{-1}$ at $50 \mathrm{~m}$ agl. and BRi number lower than 0.25 (neutral atmosphere). The average roughness length values of $0.17 \mathrm{~m}$ and $0.14 \mathrm{~m}$ were obtained for April and November, respectively. These roughness length values are typical for the land cover observed at the measurement site (Stull, 1988). The roughness length is larger in rainy season as a consequence of the change in vegetation leaf area. In addition, the roughness length did not show large variability as a function of wind direction, as shown in Fig. 8. This result was already expected due to vegetation homogeneity around measurement site.

\section{Determination of Friction Velocity, $u^{*}$}

The friction velocity, $u^{*}$, was calculated for each data record by applying Equation 2 using the mean roughness length calculated earlier and presented in Table 2 . The Fig. 9 shows the scatter plots of $u^{*}$ against BRi values for April and November. There is a large spreading of $u^{*}$ values in both months, but they are larger in rainy month (April). It can be noticed, as well, that the data spreading is larger during stable conditions of atmosphere (BRi values larger than 0.25 ).

Table 2. Physical parameters required to parameterize wind vertical profile in São João do Cariri

\begin{tabular}{lll}
\hline & Rainy Season (April) & Dry Season (November) \\
\hline Roughness length, $Z_{0}(\mathrm{~m})$ & 0.17 & 0.14 \\
Friction velocity, $u^{*}(\mathrm{~m} / \mathrm{s})$ & $0.078^{*} v(25 \mathrm{~m})+0.01^{\#}$ & $0.075 * v(25 \mathrm{~m})+0.008^{\# \#}$ \\
Power factor, $\alpha$ & 0.21 & 0.17 \\
\hline
\end{tabular}

\#-R $\mathrm{R}^{2}=0.993$

\#\# $-R^{2}=0.995$
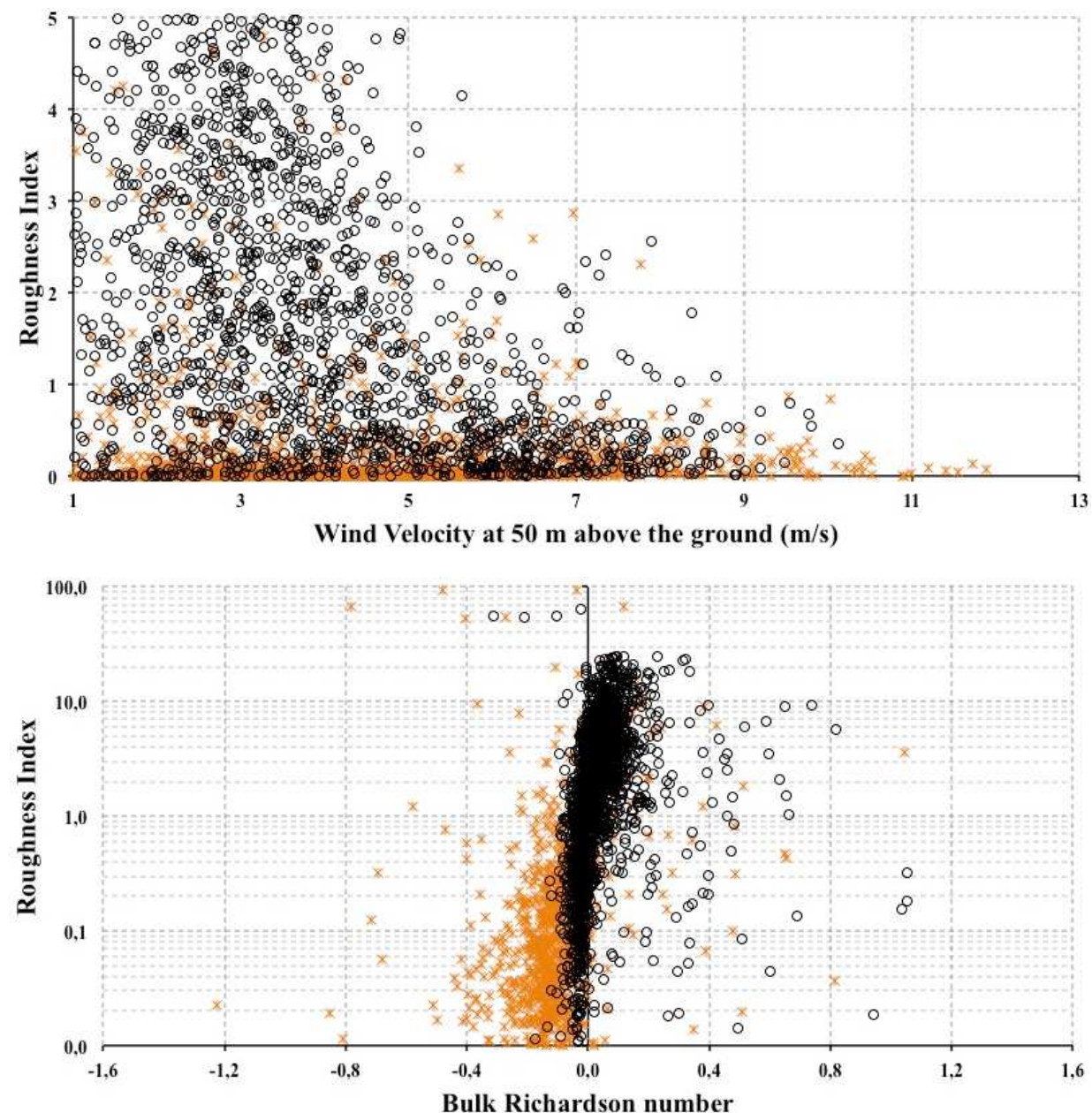

(a) 

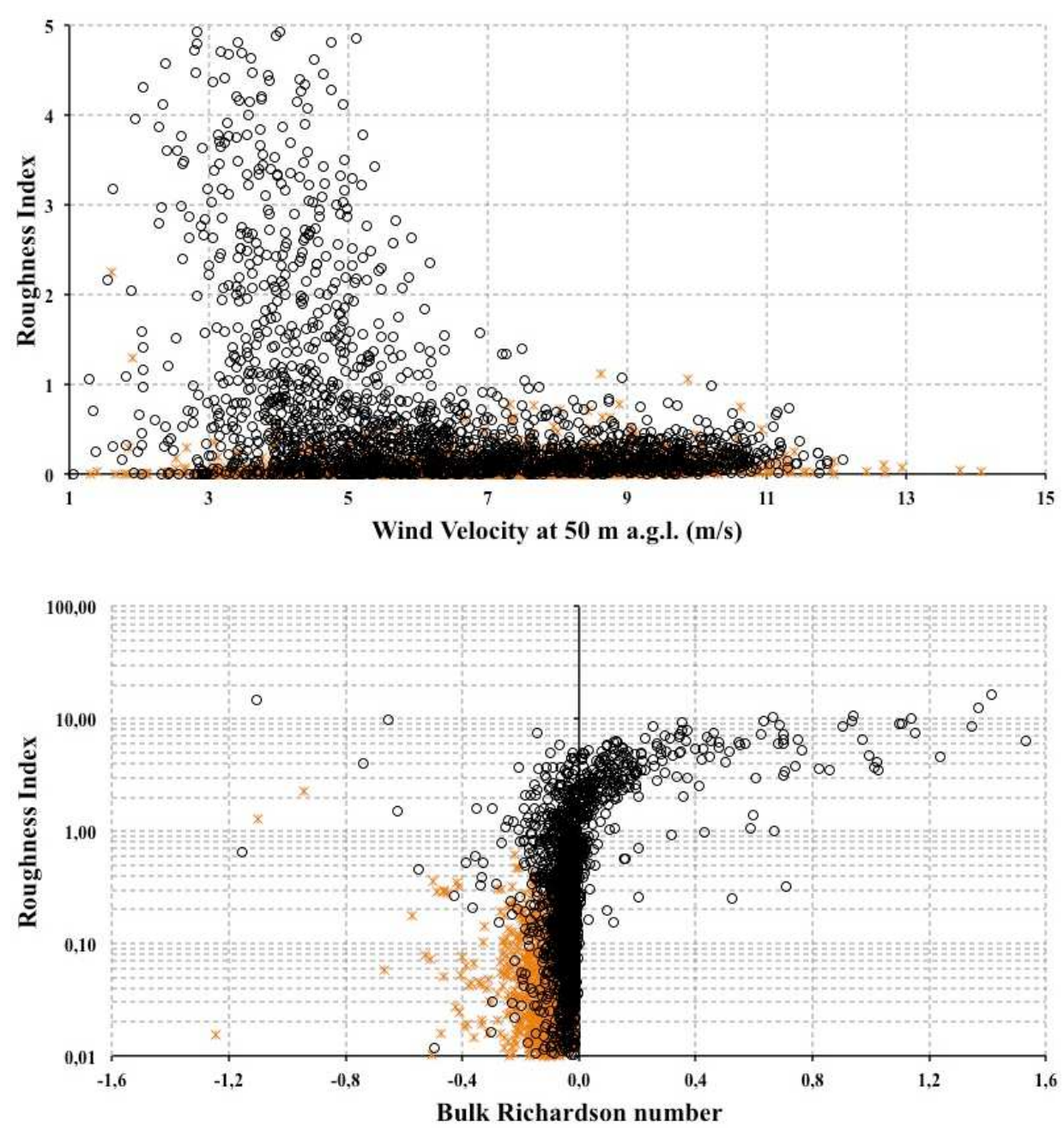

(b)

Fig. 6. (a) Scatter-plots for April presenting roughness length (in $\mathrm{m}$ ) versus wind speed at $50 \mathrm{~m}$ agl. (left) and versus BRi number (right); (b) same scatter-plots obtained for November. The orange dots represent the diurnal wind data and black circles represent nocturnal wind data

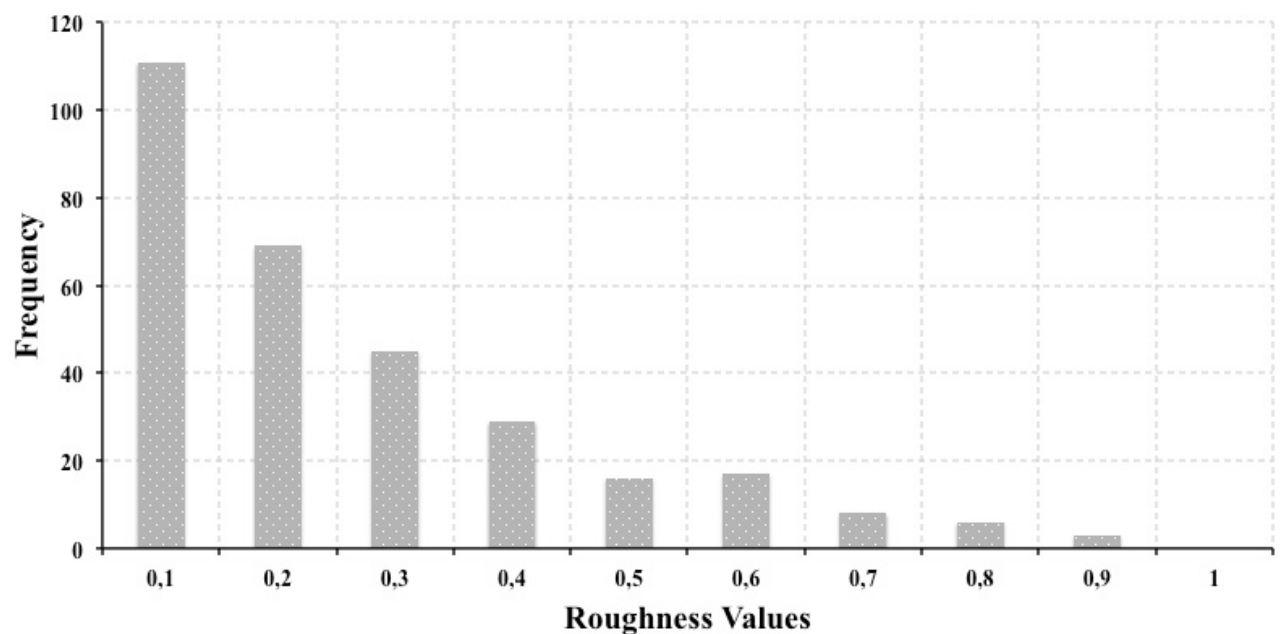

(a) 


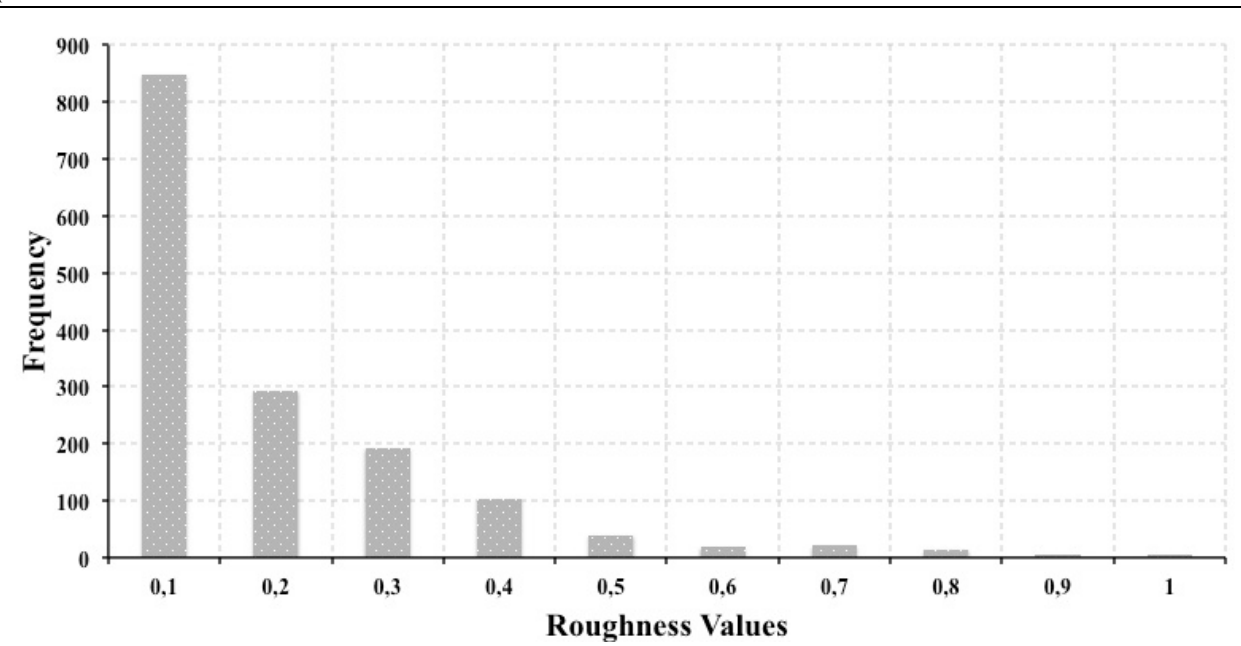

(b)

Fig. 7. (a) Frequency distribution of roughness length values in April taking into consideration only data presenting wind speed larger than $6 \mathrm{~m} \mathrm{sec}^{-1}$ at $50 \mathrm{~m}$ agl. and BRi lower than 0.25; (b) Similar as (a) for November

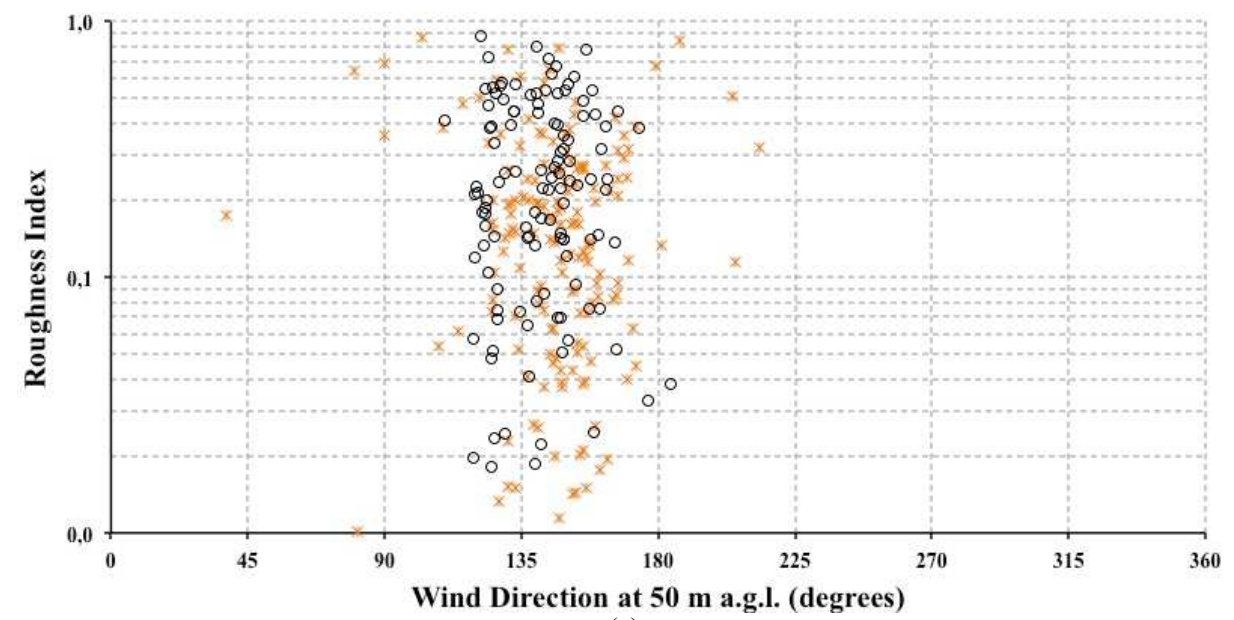

(a)

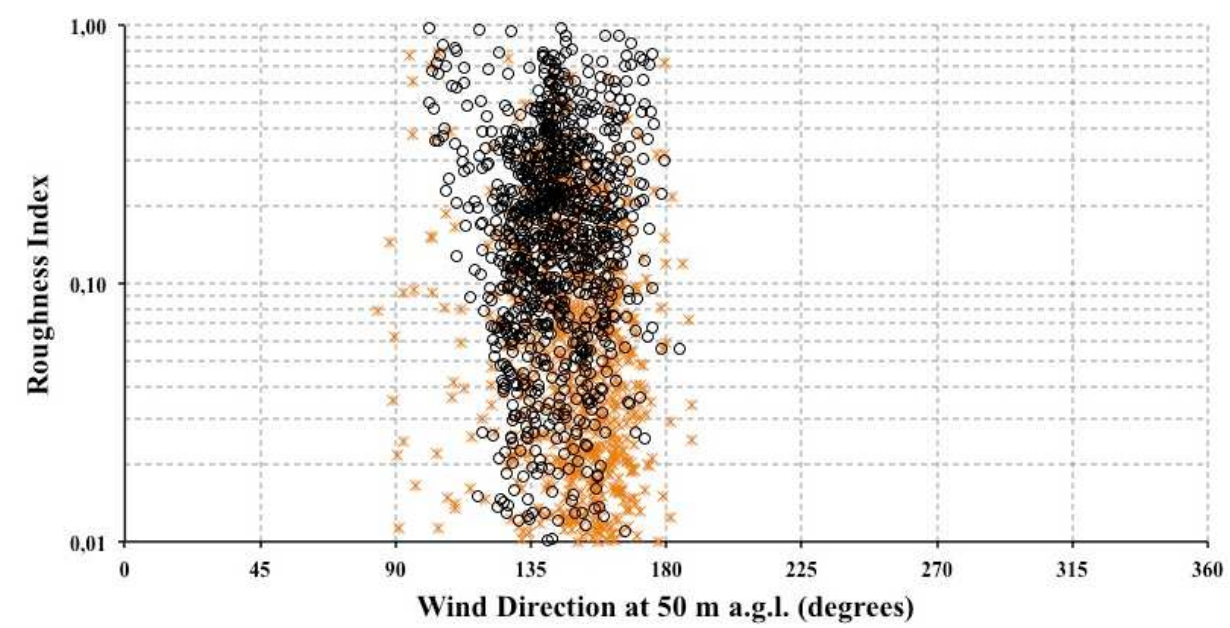

(b)

Fig. 8. Scatter-plots of surface roughness length (in $\mathrm{m}$ ) versus wind direction for April (left) and November (right) taking into consideration only data with wind speed larger than $6 \mathrm{~m} \mathrm{sec}^{-1}$. The orange dots represent the diurnal wind data and black circles represent nocturnal wind data 


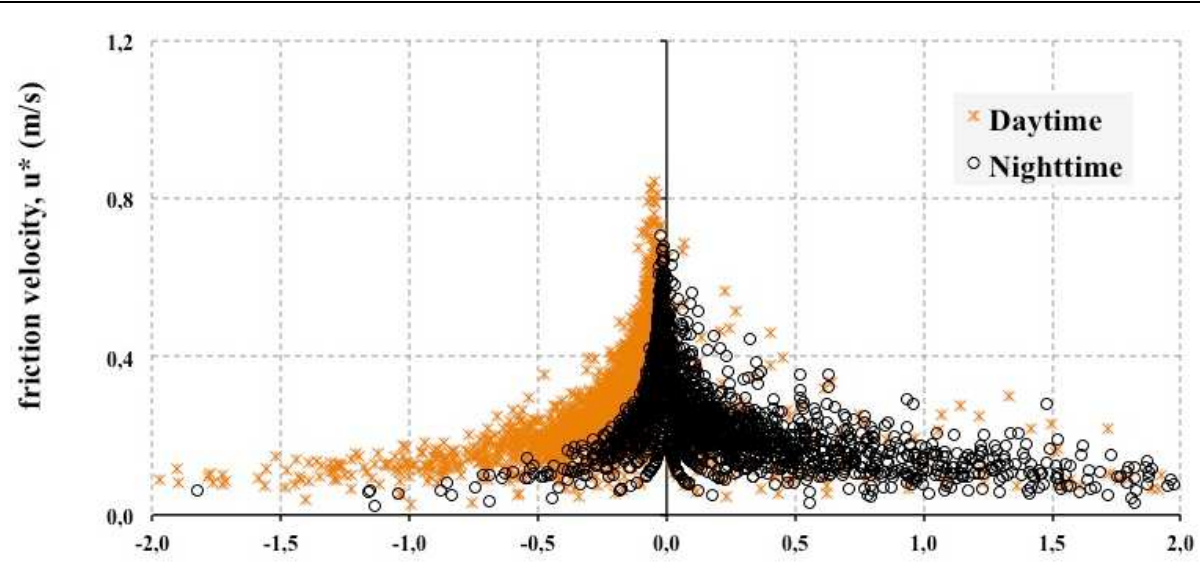

Bulk Richardson number

(a)

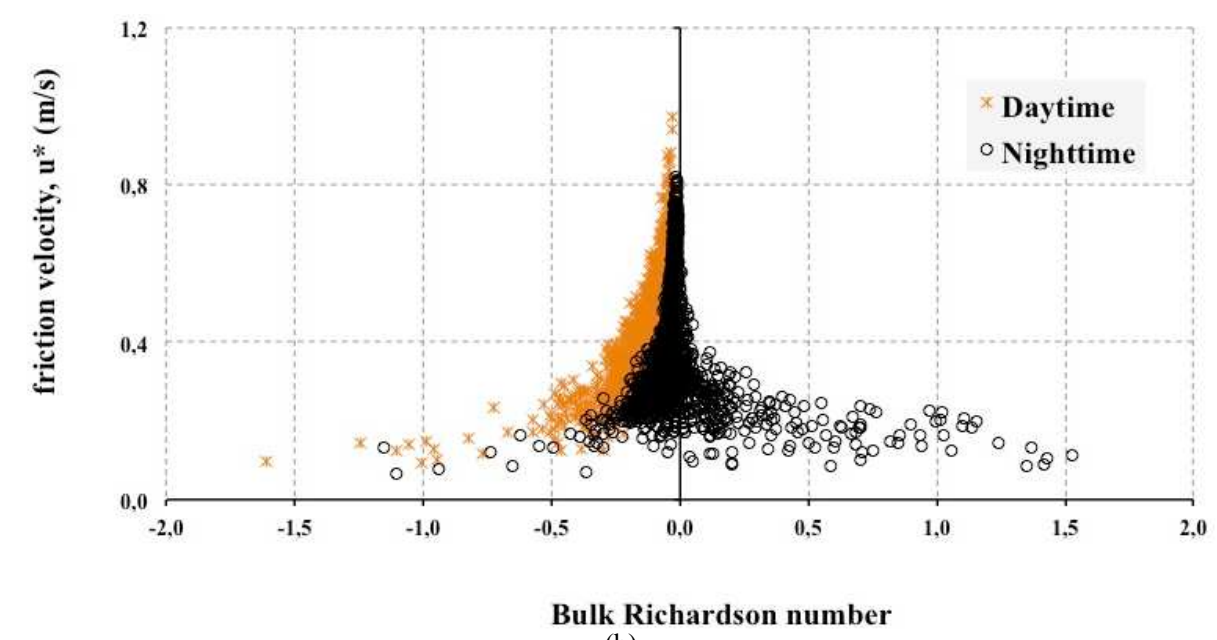

(b)

Fig. 9. Plots for friction velocity (in $\mathrm{m} / \mathrm{s}$ ) versus Bulk-Richardson number: April (left) and November (right)

The Fig. 10 presents the graphs of friction velocity $\left(u^{*}\right)$ versus wind velocity at $25 \mathrm{~m}$ agl. $(v 25 \mathrm{~m})$. As expected, the graphs pointed out a linear relationship between both variables for both months. Table 2 presents the parameters, $a$ and $b$, obtained by fitting a linear function to estimate $u^{*}$ from $v 25 \mathrm{~m}$ :

$$
u^{*}=a_{\cdot V 25 m}+b
$$

Assuming that the fitted linear function between $u^{*}$ and $v 25 m$ is typical for each season (dry or rainy), it is possible to estimate the wind velocity at any height agl. provided that wind data acquired at $25 \mathrm{~m}$ agl. Is available.

\section{Determination of Power Factor, $\alpha$}

In a similar way, the power factor, $a$, was also Fig. 11 shows that the large spreading of $a$ values occurred during the nocturnal hours when the stable conditions prevail. Similar to the procedure used for friction velocity, the relationship between power factor and $v 25 \mathrm{~m}$ was investigated. The Fig. 12 shows that $a$ tends to achieve a constant value for larger values of $v 25 \mathrm{~m}$. The constant $a$ value was estimated by an iterative fitting procedure stopped when the lower Root Mean Square Error was achieved. The Table 2 presents the $a$ values obtained for April and November.

\section{Estimation of Wind Velocity at $50 \mathrm{~m}$ agl. by Using Logarithmic Law}

The estimates for wind speed at $50 \mathrm{~m}$ agl., v50m, was obtained from log law described in Equation 2. Wind velocity at $25 \mathrm{~m}$ agl. acquired in four months at SJC was used as input. Data acquired in April and May were used to evaluate the performance during the rainy season; and data acquired in October and November were used for the dry season. The roughness length and the empirical linear function for friction velocity are listed in Table 2 for each season.

The deviations of wind speed estimates were low and the Pearson correlation coefficients were above 0.95 in all months (Table 3). The Fig. 13 presents the scatter plot 
comparing estimated and observed values of $v 50 \mathrm{~m}$. The deviations were larger in rainy months than dry ones, probably due to the typical instability conditions that happen during the rainy season.

The Fig. 14 presents a comparison of wind velocity distributions-observed and estimated- for the four months. It can be noticed that the frequency distributions presented by wind speed estimates are very similar to the observed wind data in all months.

\section{Estimation of Wind Velocity at $50 \mathrm{~m}$ agl. by using Exponential Law}

Similar evaluation was done to estimate the wind speed $v 50 \mathrm{~m}$ by using the exponential approach described in Equation 3 and $\alpha$ values presented in Table 2. Data acquired in April and May were used to evaluate the performance during the rainy season; and data acquired in October and November were used for the dry season. The results were very similar to the ones obtained by using log law. Table 4 presents the deviations and Pearson correlation. It can be noticed, by comparing Table 3 and 4, that exponential approach provided wind speed estimates with lower BIAS deviations than log law in rainy season. The Pearson correlation coefficients between observed $v 50 \mathrm{~m}$ and estimated $v 50 \mathrm{~m}$ data provided by both methods achieved the same values between the observed $v 50 \mathrm{~m}$ and $v 25 m$ data. Remember that $v 25 m$ was used as input in both methods. The deviations provided by both methods were similar for dry season (October and November).

The Fig. 15 presents the scatter plots for estimated versus observed wind speed values. It can be noticed that the frequency distributions presented by estimated wind speeds are very similar to the observed wind data. Although the exponential approach provided the lowest BIAS deviation along the wet season, it presented larger overestimation of wind speeds above $7 \mathrm{~m} \mathrm{sec}^{-1}$ than the log law approach as indicated by the plots in frames (a) and (b) of Fig. 13 and 15.

The estimated wind velocity, provided by both approaches, presented quite the same reliability along the dry season. The BIAS and RMSE deviations were almost equal and both methodologies presented similar behavior as demonstrated by the plots in frames (c) and (d) of the Fig. 13 and 15.

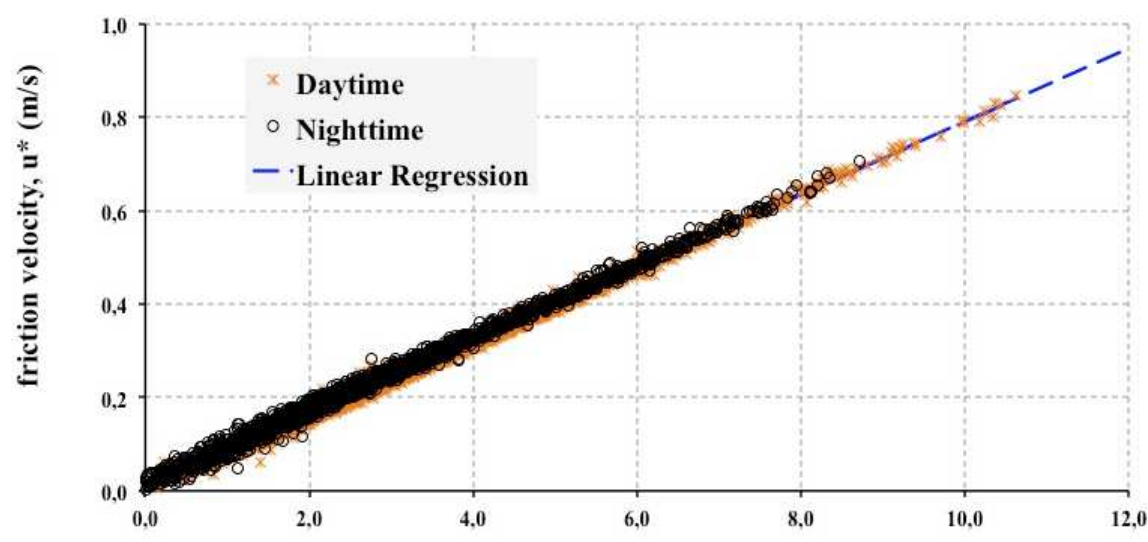

wind velocity at $25 \mathrm{~m}$ agl. $(\mathrm{m} / \mathrm{s})$

(a)

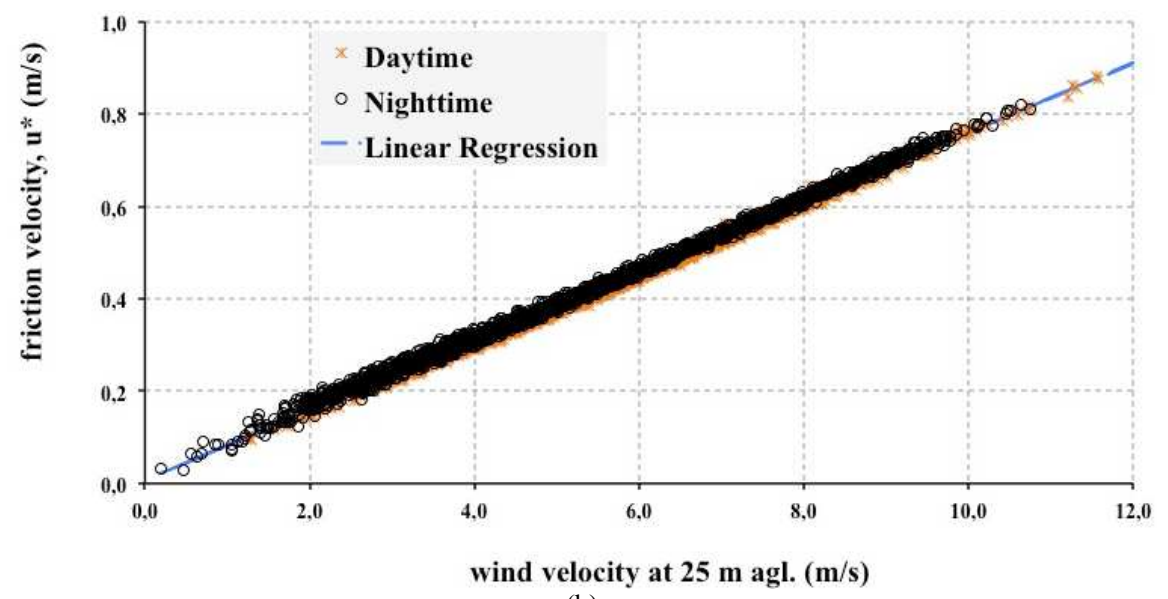

(b)

Fig. 10. Linear regression fitting for friction velocity (in $\mathrm{m} / \mathrm{s}$ ) versus wind speed at $25 \mathrm{~m}$ agl.: April (left) and November (right) 


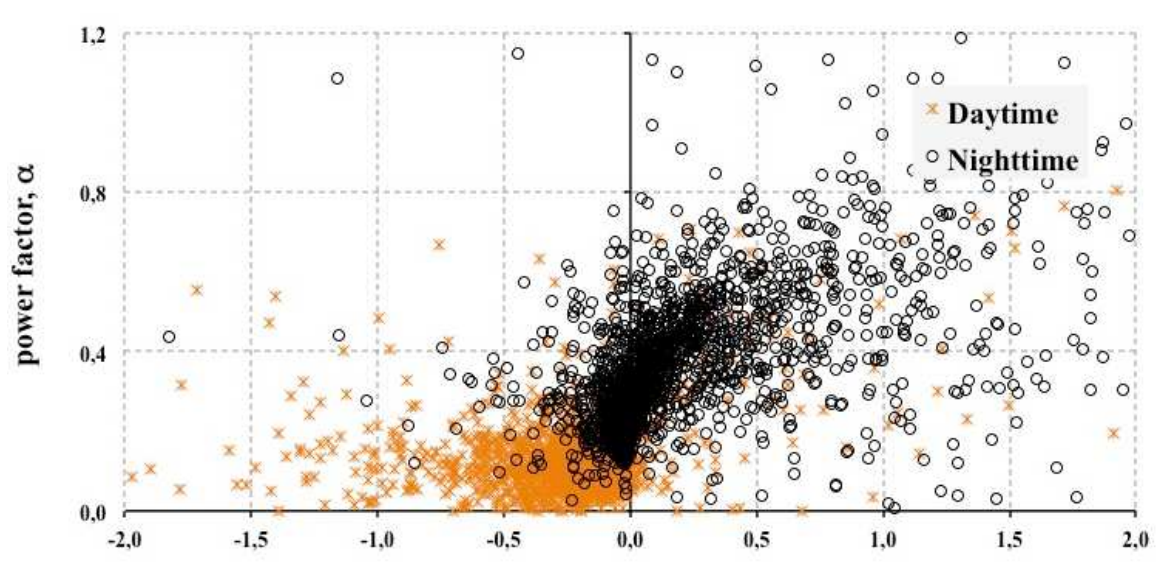

Bulk Reynolds number

(a)

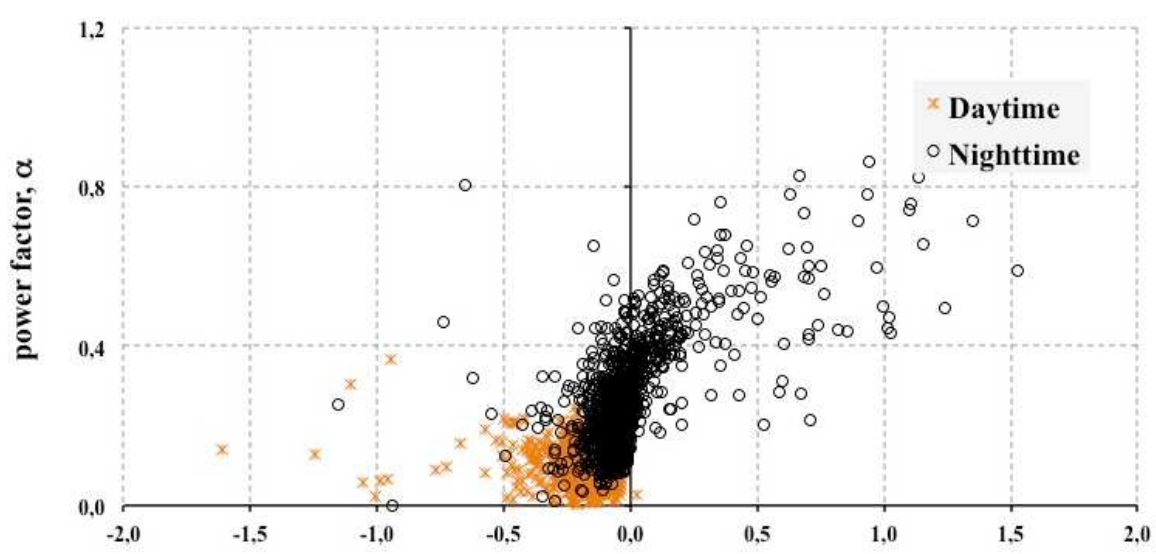

Bulk Richardson number

(b)

Fig. 11. Plots for power factor $(\alpha)$ versus Bulk-Richardson number in April (left) and November (right)

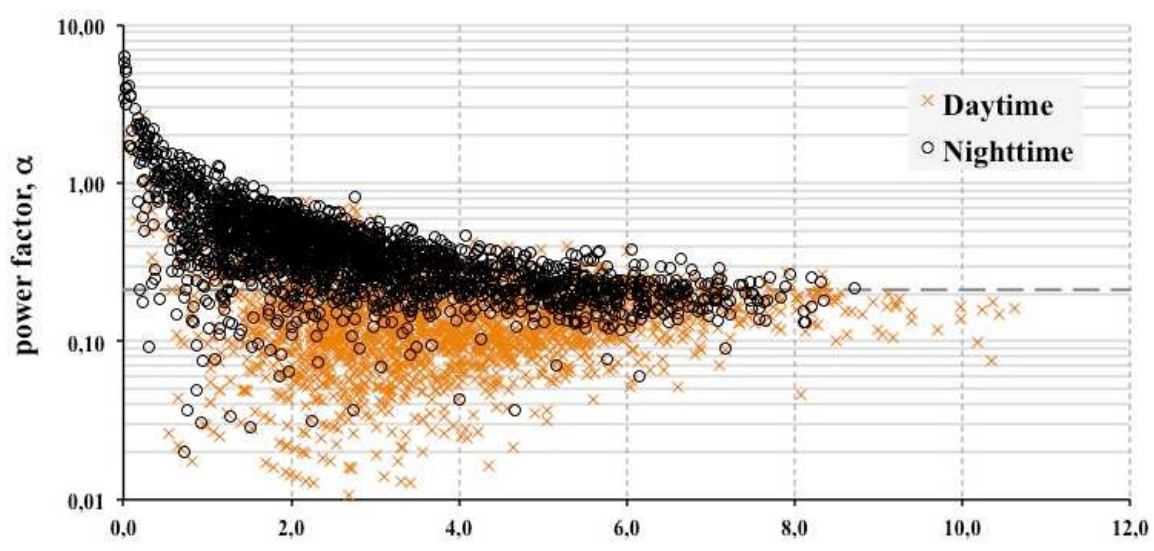

wind velocity at $25 \mathrm{~m}$ agl. $(\mathrm{m} / \mathrm{s})$

(a) 


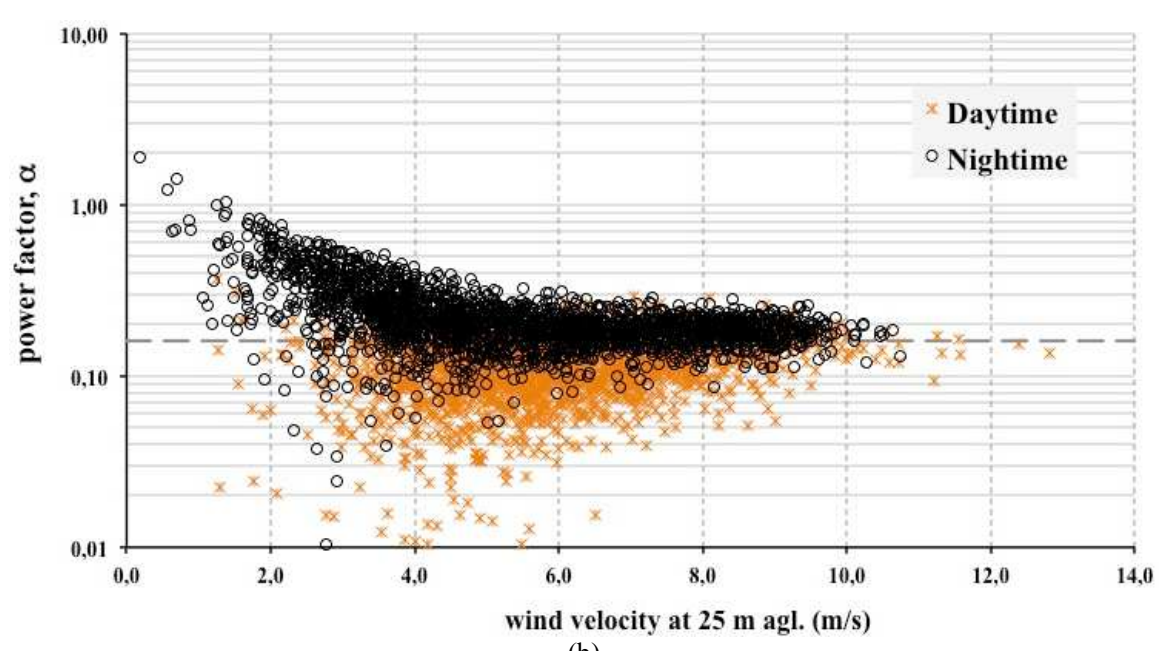

(b)

Fig. 12. Behavior of power factor as a function of wind speed at $25 \mathrm{~m}$ agl.: April (left) and November (right). The dashed line shows the a values estimated by using an iterative fitting procedure to minimize the mean square error

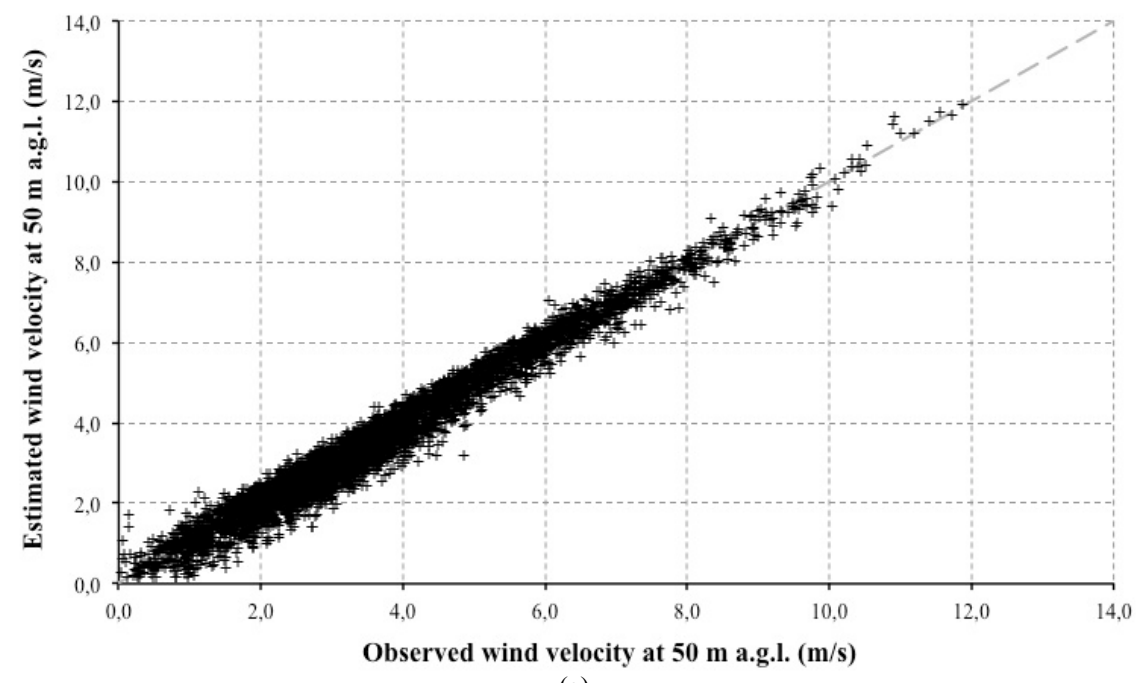

(a)

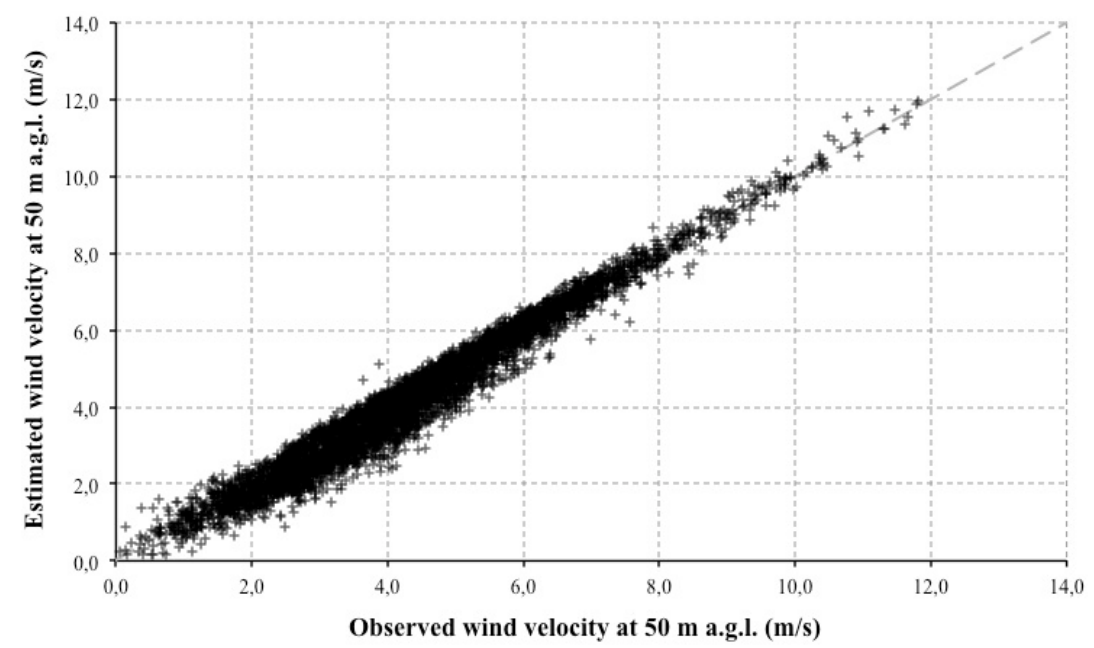

(b) 


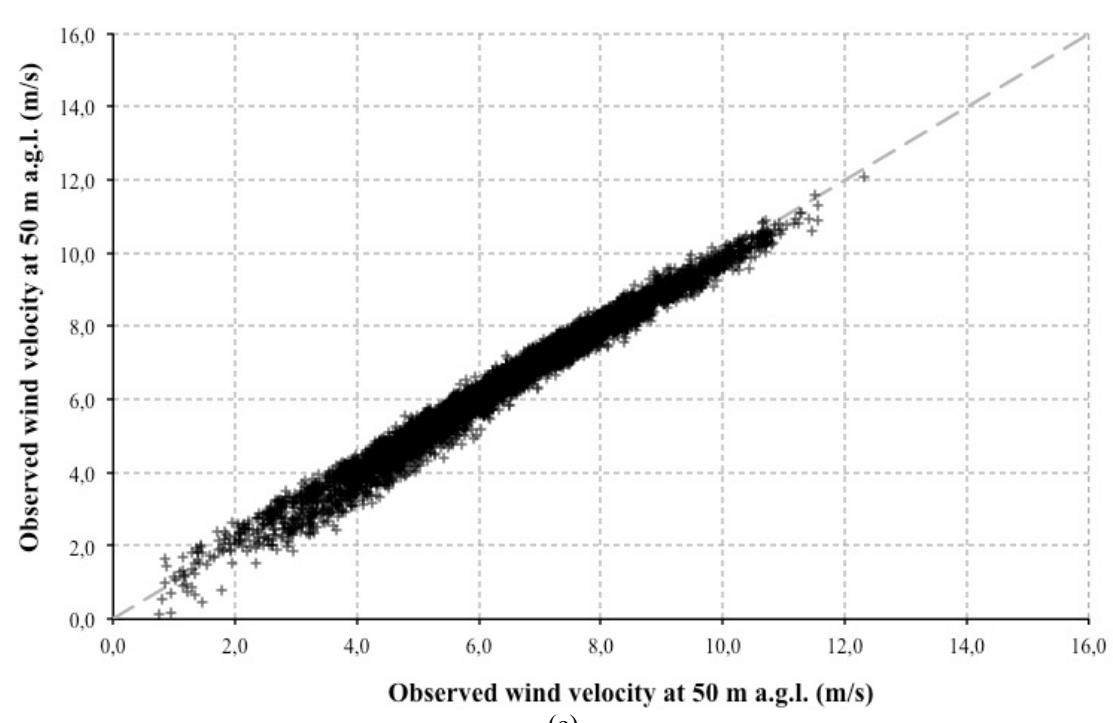

(c)

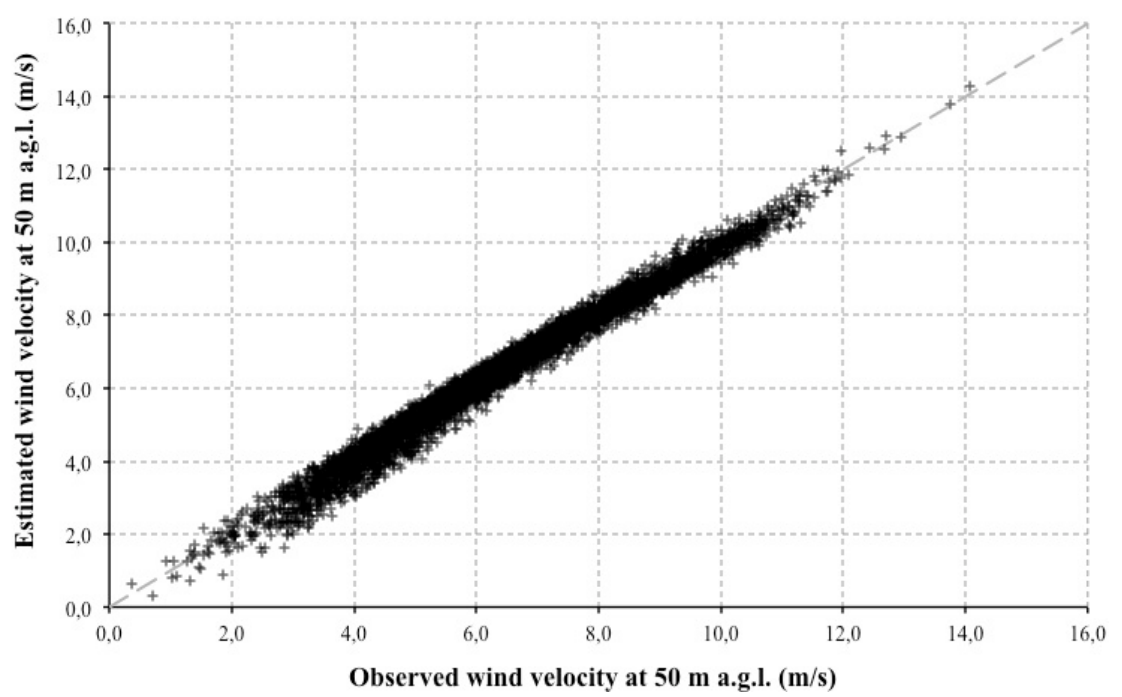

(d)

Fig. 13. Estimated versus observed wind velocity at $50 \mathrm{~m}$ agl. for (a) April, (b) May, (c) October and (d) November 2006. The wind estimates were obtained by using $Z_{0}$ and $u^{*}$ presented in Table 2 into the log law equation described in (2)

Figure 16 presents a comparison of wind velocity distributions obtained for the four months. The use of $\log$ law allowed a better representation of the wind speed distributions at $50 \mathrm{~m}$ agl. along both seasons, as pointed out by Fig. 14 and 16. The largest discrepancies between estimated and observed wind speed distributions occurred for wind speeds lower than $7 \mathrm{~m} \mathrm{sec}^{-1}$ when atmospheric stability has a major influence in vertical wind velocity profile.

\section{Sensitivity Analysis on Shear Parameters}

Finally, sensitivity analyses were performed to evaluate how the deviations on $Z_{0}$ and $a$ values can influence the confidence on vertical wind profile.
Table 5 presents the statistical deviations for $v 50 \mathrm{~m}$ estimates from exponential approach using $a$ values $10 \%$ larger or lower than the value listed in Table 2. It can be noticed that the BIAS deviation of estimated $v 50 \mathrm{~m}$ is highly influenced by the value of power factor, $a$, used in exponential approach for vertical wind profile. The Table 5 shows that a $\pm 10 \%$ variation on $a$ value can move the BIAS deviation from an underestimation to an overestimation of wind speed in rainy season. The sensitivity was lower during dry season, but it still can move from negative to positive BIAS. Keep in mind that each $1 \%$ variation on BIAS deviation corresponds roughly to $3 \%$ variation in wind power density. 
Table 3. Statistical deviations and Pearson correlation presented by wind speed estimates provided by using log law and shear parameters presented in Table 2. Percentage values are the relative values regarding to the average of observed mean wind speed

\begin{tabular}{llllll}
\hline & BIAS & & RMSE & & \\
& $-\mathrm{m} / \mathrm{s}$ & $\%$ & $\mathrm{~m} / \mathrm{s}$ & $\%$ & Pearson correlation \\
\hline April (rainy season) & -0.05 & -1.1 & 0.35 & 9.3 & 0,99 \\
May (rainy season) & -0.14 & -3.3 & 0,42 & 9.5 & 0,98 \\
October (dry season) & -0.02 & -0.3 & 0.30 & 4.7 & 0,99 \\
November (dry season) & 0.01 & 0.2 & 0.30 & 4.7 & 09 \\
\hline
\end{tabular}

Table 4. Statistical deviations and pearson correlation presented by wind speed estimates provided by exponential approach. Percentage values are regarding to the average of observed mean wind speed

\begin{tabular}{|c|c|c|c|c|c|}
\hline & \multicolumn{2}{|c|}{ BIAS } & \multicolumn{2}{|c|}{ RMSE } & \multirow[b]{2}{*}{ Pearson correlation } \\
\hline & $\mathrm{m} / \mathrm{s}$ & $\%$ & $\mathrm{~m} / \mathrm{s}$ & $\%$ & \\
\hline April (rainy season) & -0.04 & 1.0 & 0.38 & 9.8 & 0,98 \\
\hline May (rainy season) & -0.11 & 2.6 & 0.45 & 10.0 & 0,98 \\
\hline October (dry season) & -0.02 & -0.3 & 0.30 & 4.7 & 0,99 \\
\hline November (dry season) & 0.01 & 0.2 & 0.31 & 4.8 & 0,99 \\
\hline
\end{tabular}

Table 5. Statistical deviations presented by wind speed estimates provided by exponential approach using $a$ values fluctuating $\pm 10 \%$ around the value listed in Table 2

\begin{tabular}{|c|c|c|c|c|c|}
\hline & \multicolumn{2}{|c|}{ BIAS } & \multicolumn{2}{|c|}{ RMSE } & \multirow[b]{2}{*}{$\alpha$ variation } \\
\hline & $\mathrm{m} / \mathrm{s}$ & $\%$ & $\mathrm{~m} / \mathrm{s}$ & $\%$ & \\
\hline \multirow[t]{2}{*}{ Rainy season } & -0.13 & -3.5 & 0.39 & 10.3 & $-10 \%$ \\
\hline & 0.05 & 1.5 & 0.40 & 10.6 & $+10 \%$ \\
\hline \multirow[t]{2}{*}{ Dry season } & -0.07 & -1.1 & 0.31 & 4.9 & $-10 \%$ \\
\hline & 0.10 & 1.6 & 0.33 & 5.2 & $+10 \%$ \\
\hline
\end{tabular}

Table 6. Statistical deviations presented by wind speed estimates provided by log law approach using $Z 0$ values fluctuating $\pm 10 \%$ around its calculated value

\begin{tabular}{|c|c|c|c|c|c|}
\hline & \multicolumn{2}{|l|}{ BIAS } & \multicolumn{2}{|c|}{ RMSE } & \multirow[b]{2}{*}{$Z_{0}$ variation } \\
\hline & $\mathrm{m} / \mathrm{s}$ & $\%$ & $\mathrm{~m} / \mathrm{s}$ & $\%$ & \\
\hline \multirow{2}{*}{ Rainy season } & -0.12 & -3.1 & 0.36 & 9.6 & $-10 \%$ \\
\hline & 0.05 & 1.3 & 0.36 & 9.6 & $+10 \%$ \\
\hline \multirow{2}{*}{ Dry season } & 0.14 & 2.1 & 0.34 & 5.3 & $-10 \%$ \\
\hline & -0.10 & -1.6 & 0.31 & 4.9 & $+10 \%$ \\
\hline
\end{tabular}

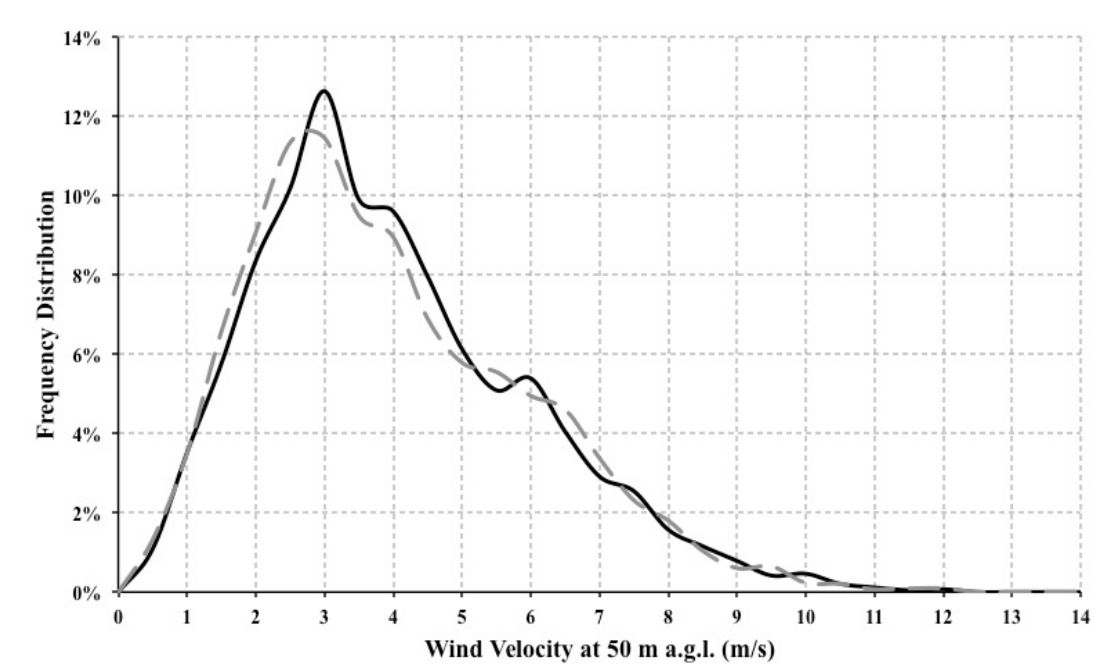

(a) 


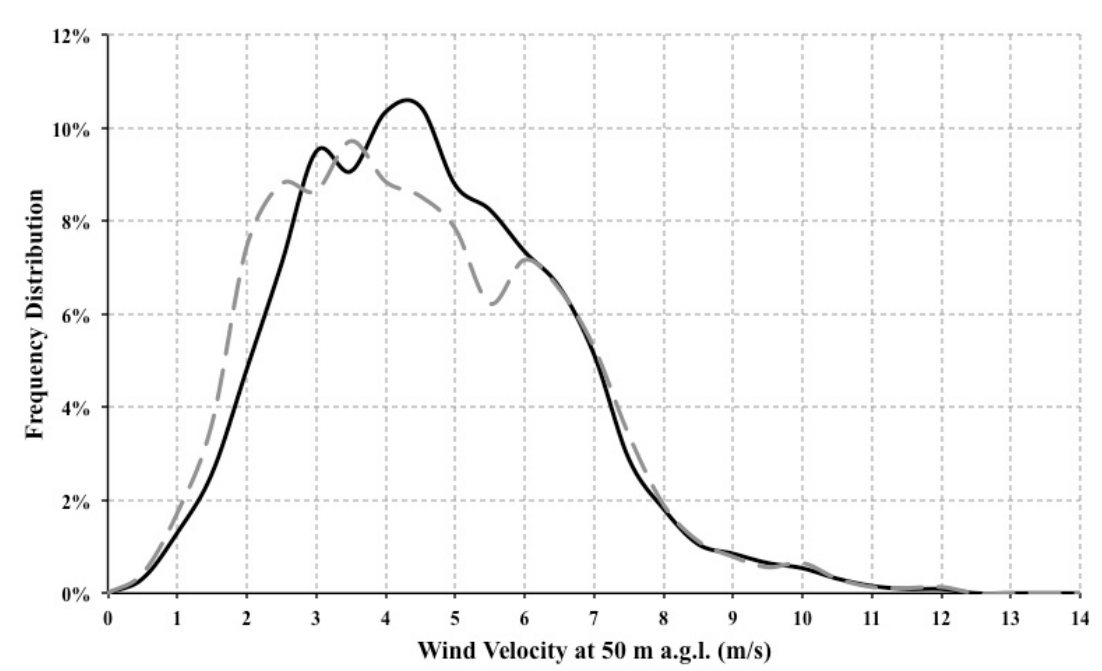

(b)

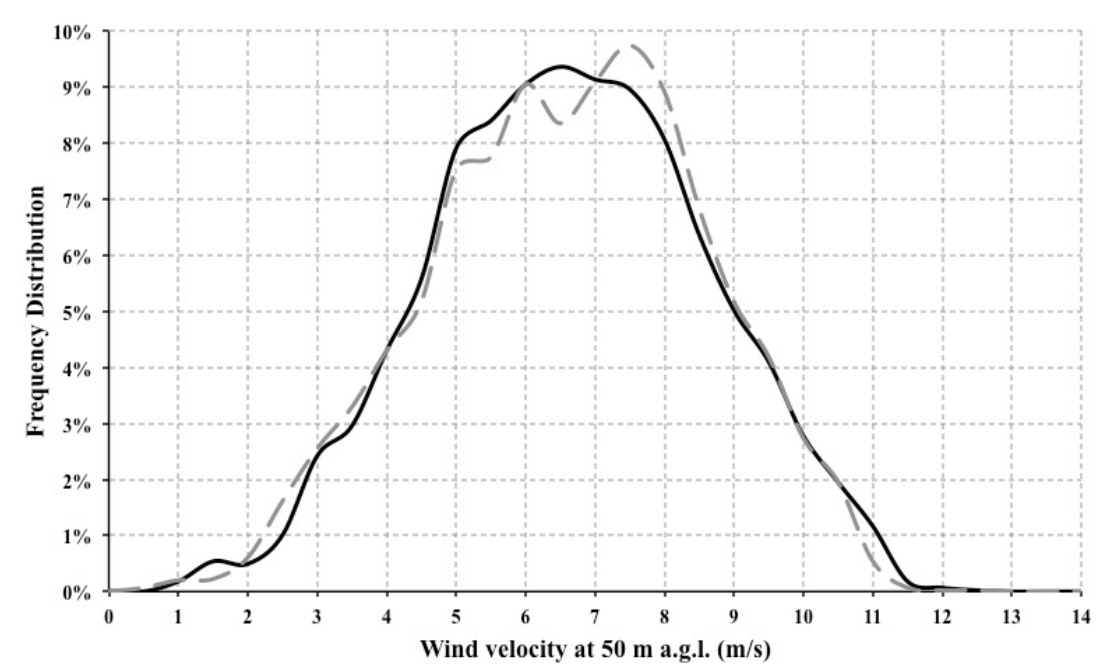

(c)

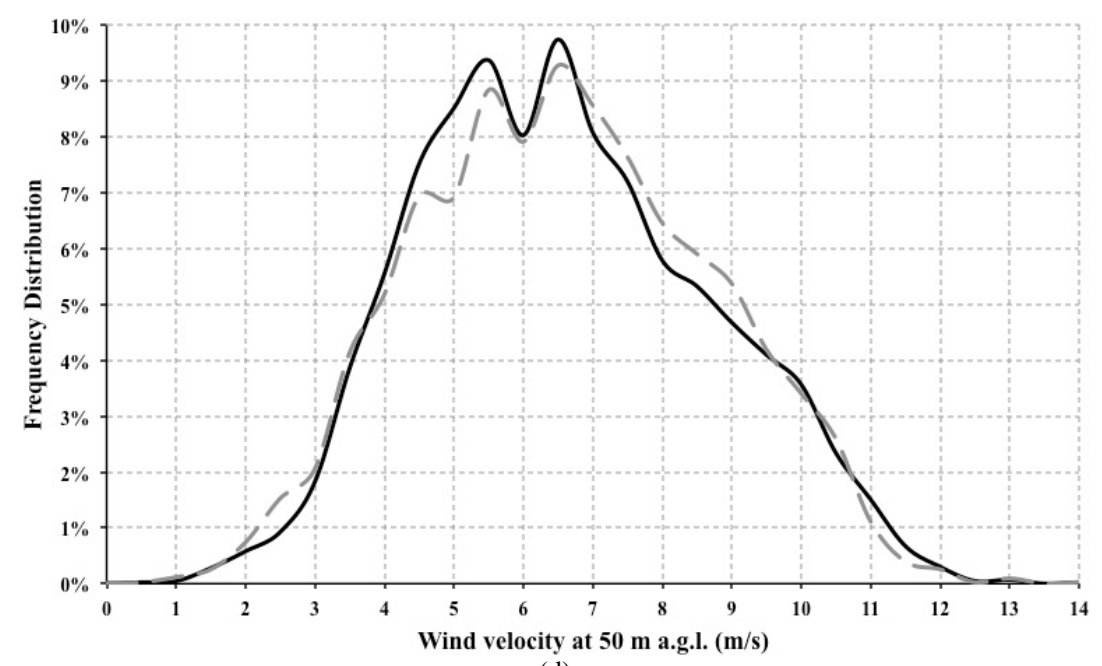

(d)

Fig. 14. Estimated (grey line) and observed (black line) wind speed distributions for (a) April, (b) May, (c) October and (d) November 2006. The wind speed estimates were obtained by using $Z_{0}$ and $u^{*}$ listed in Table 2 into the log law equation described in (2) 


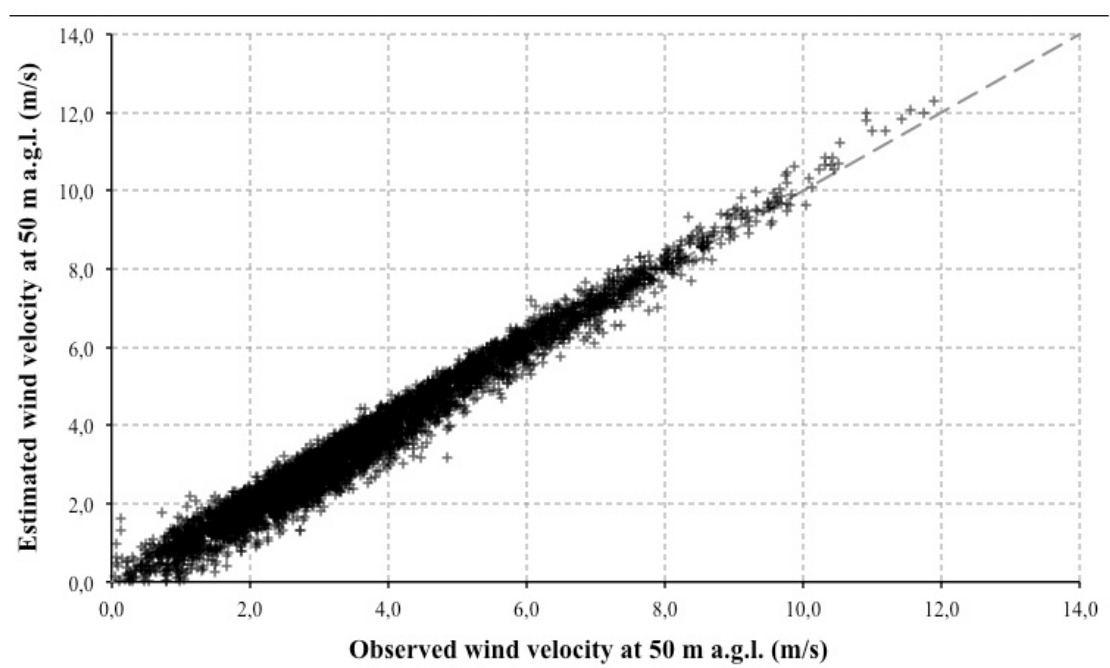

(a)

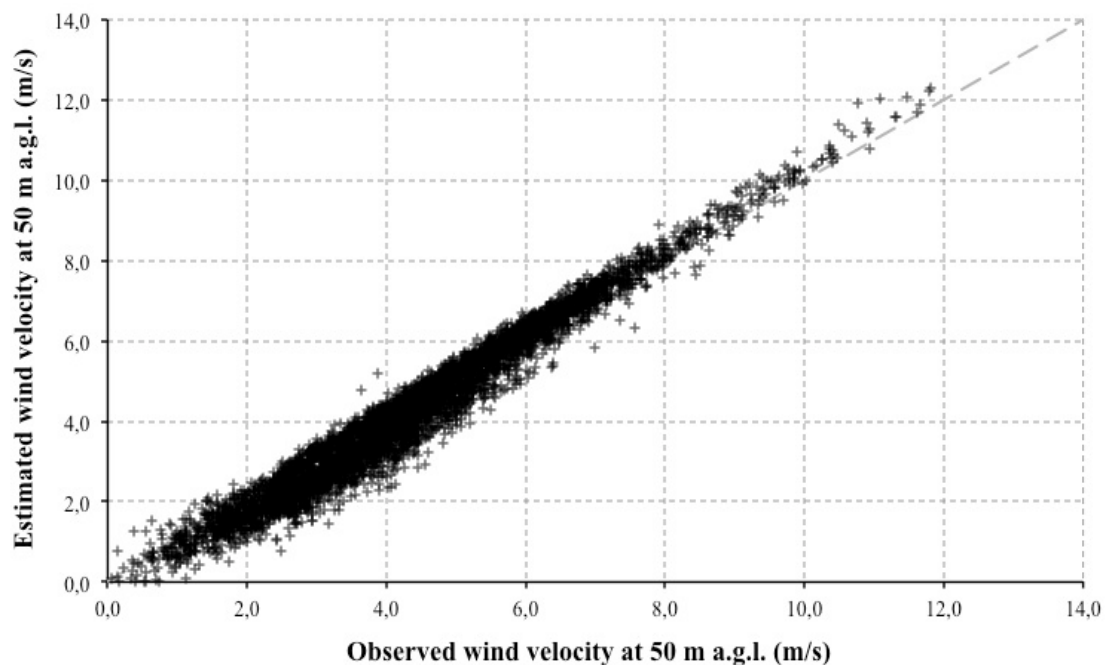

(b)

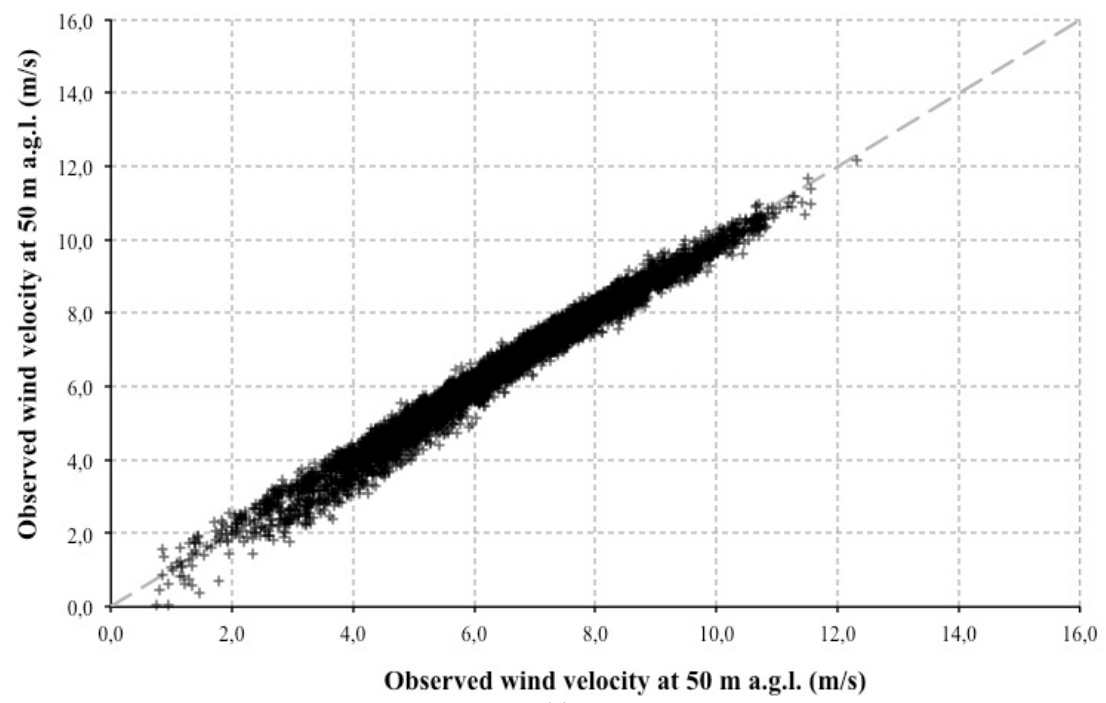

(c) 


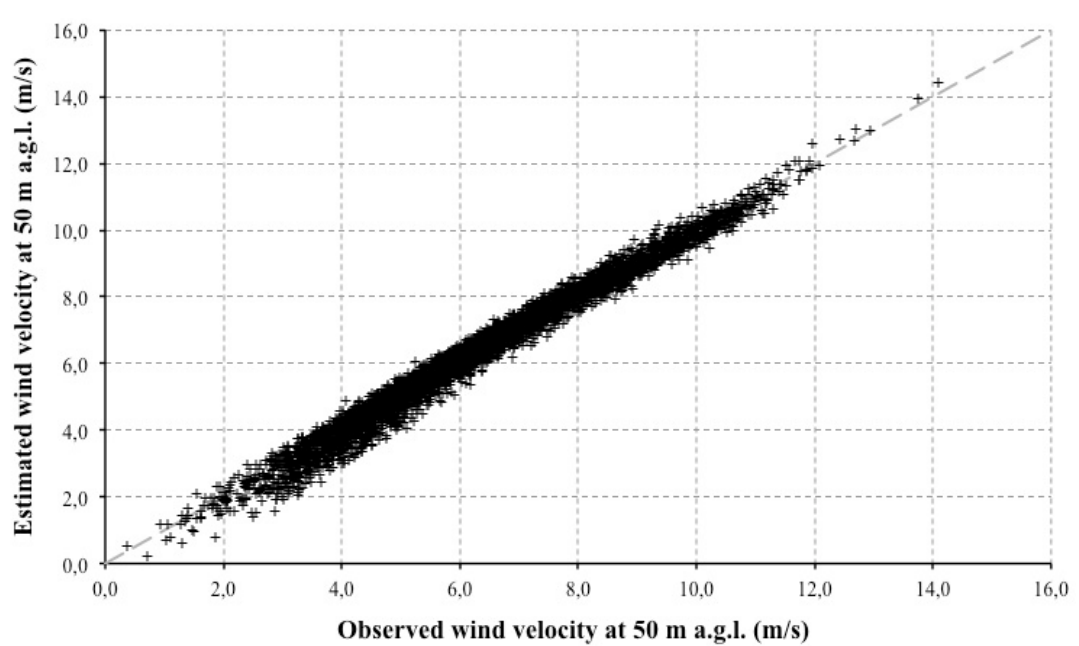

(d)

Fig. 15. Estimated versus observed wind velocity at $50 \mathrm{~m}$ agl. for (a) April, (b) May, (c) October and (d) November 2006. The estimated wind speeds were obtained by using the exponential approach described in Equation 3 and $\alpha$ values listed in Table 2

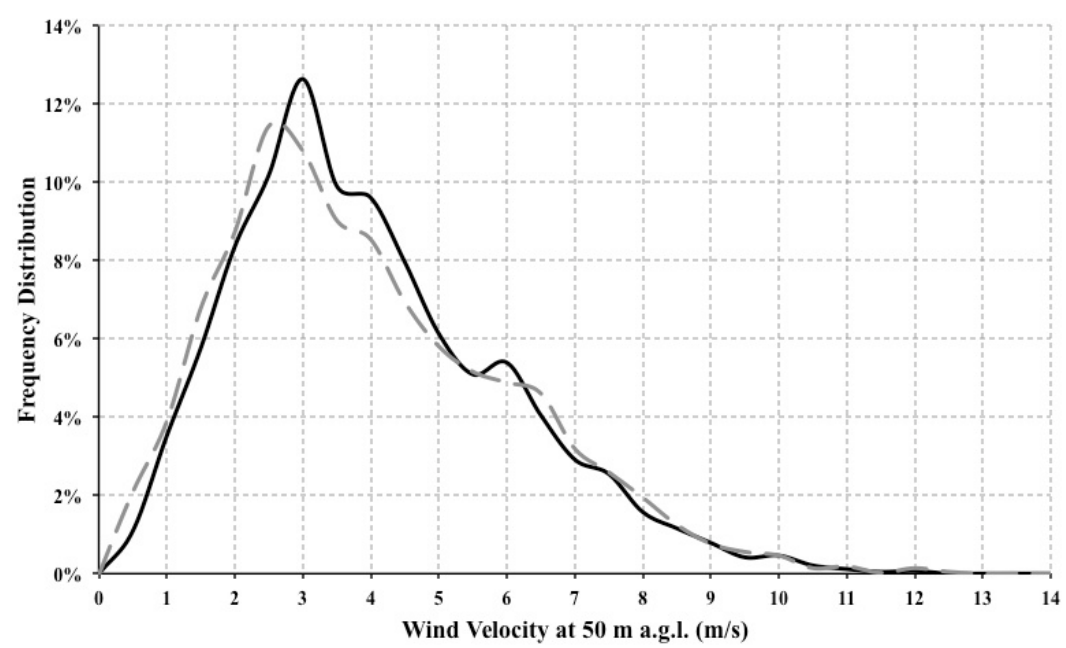

(a)

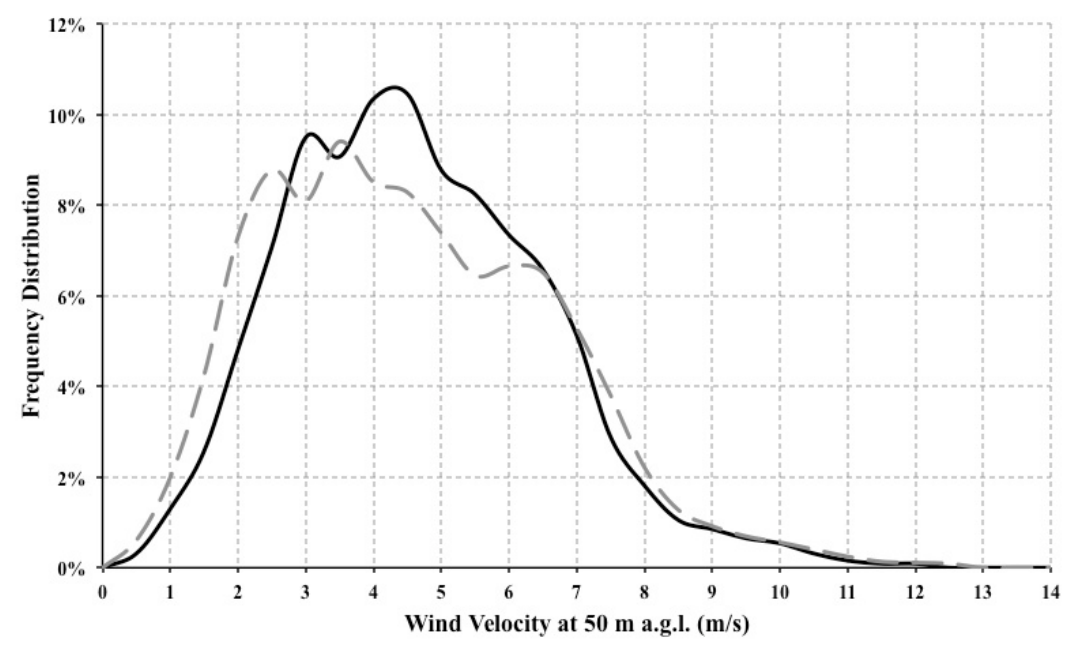

(b) 


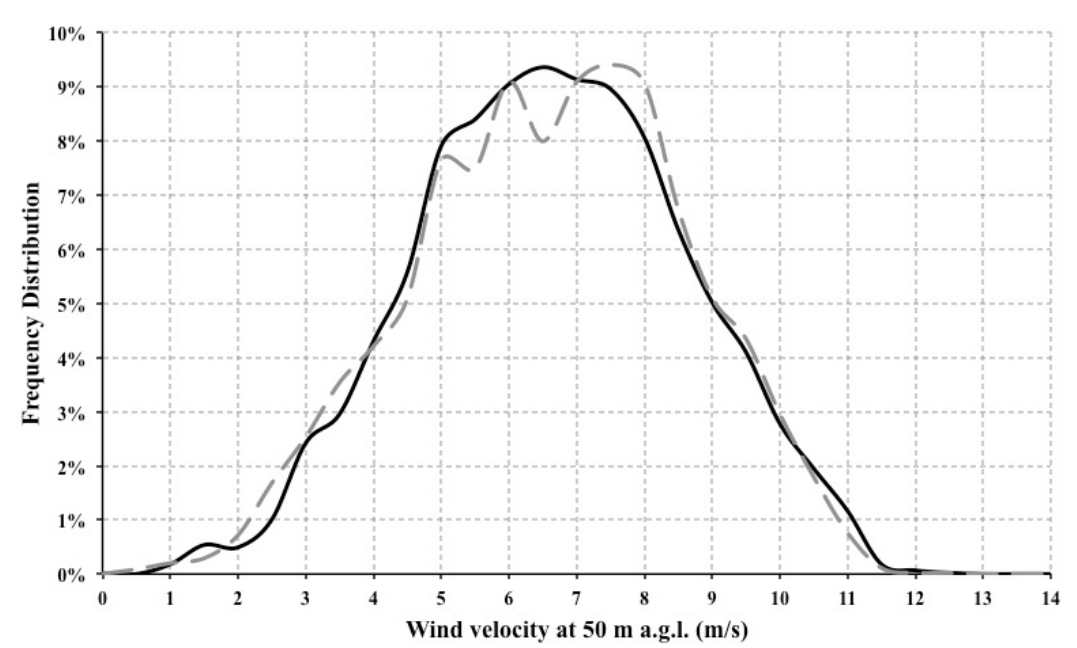

(c)

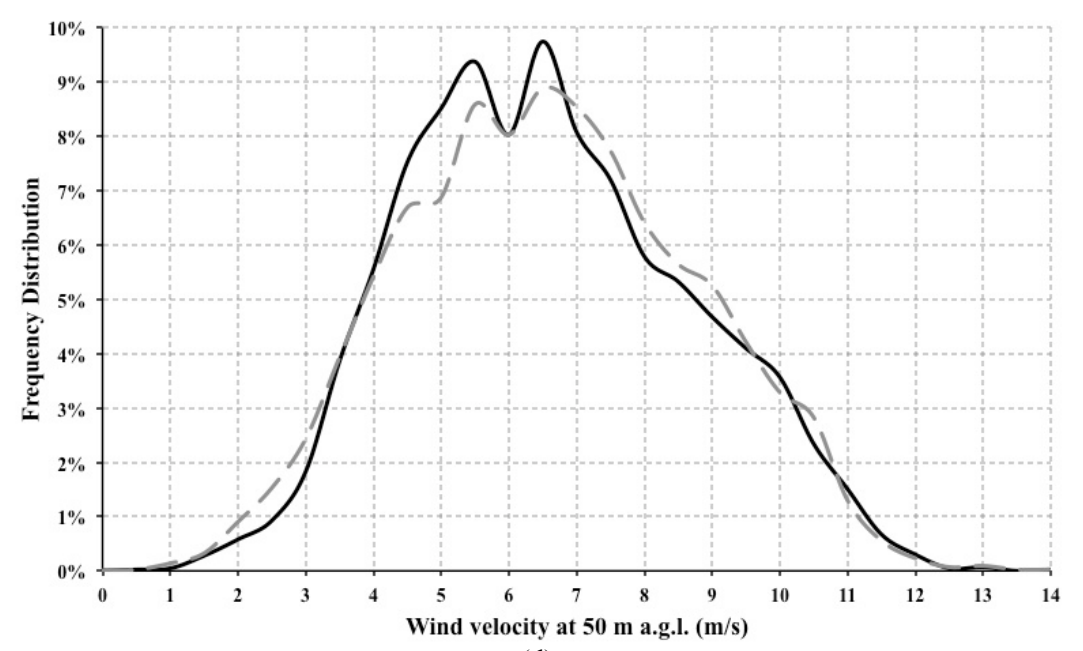

(d)

Fig. 16. Estimated (grey line) and observed (black line) wind speed distributions for (a) April, (b) May, (c) October and (d) November 2006. The estimated wind speeds were obtained by using the exponential approach described in Equation 3 and $\alpha$ values listed in Table 2

Similar results were obtained for sensitivity analysis taking into consideration a $\pm 10 \%$ variation around the $Z_{0}$ values listed in Table 2 for each season. Table 6 presents the statistical deviations for $v 50 \mathrm{~m}$ estimates in this analysis. Again only the BIAS deviation from estimated $v 50 \mathrm{~m}$ is highly influenced by $Z_{0}$ variation. The BIAS deviation moved from a wind speed underestimation $(-3.1 \%)$ to an overestimation $(1.3 \%)$ in rainy season. The sensitivity was high during dry season as well. The BIAS deviation moves from 2.1 to $-1.6 \%$ in dry season for $\pm 10 \%$ variation in $Z_{0}$. In other words, if roughness length is set up $10 \%$ higher than the actual value, the estimated wind power density at $50 \mathrm{~m}$ height provided by $\log$ law approach would be underestimated around 5\% during the dry season.

\section{Conclusion}

This work describes a methodology to evaluate the wind shear parameters-roughness length $\left(Z_{0}\right)$, power factor $(\alpha)$ and friction velocity $\left(u^{*}\right)$ - from data acquired in wind masts. The obtained results demonstrated the importance in considering atmospheric stability conditions at the moment of measurement in order to get reliable values for the shear parameters. The BulkRichardson number and statistical analysis were used to discard all data related to highly stable or unstable atmospheric conditions preventing any unsuitability with the Monin-Obukov theory.

In a second step, the shear parameters together with wind speed data acquired at $25 \mathrm{~m}$ agl. were used to estimate the wind speed at $50 \mathrm{~m}$ height in order to evaluate the performance of exponential approach and 
logarithmic law in providing the local vertical wind profile. The results showed that both methods were able to produce consistent vertical wind profile data for dry and rainy seasons in São João do Cariri. The major differences between both methods occurred for rainy season when exponential approach presented lower BIAS deviations. However, the exponential approach overestimates wind velocities larger than $7 \mathrm{~m} \mathrm{sec}^{-1}$. Both methods were also capable to simulate the wind speed distribution at $50 \mathrm{~m}$ height, mostly at the largest wind velocities $\left(v 50 m>7 \mathrm{~m} \mathrm{sec}^{-1}\right)$.

\section{Acknowledgement}

The authors thank to CNPq by the financial support. Thanks are also due to the technical support team at Laboratory for Meteorological Instrumentation, responsible for the wind masts operation and maintenance. Finally, the authors acknowledge Silvia Pereira and Rafael Chagas for their valuable IT technical and support contribution.

\section{Author's Contributions}

All authors equally contributed in this work.

\section{Ethics}

This article is original and contains unpublished material. The corresponding author confirms that all of the other authors have read and approved the manuscript and no ethical issues involved.

\section{References}

Araujo, K.D., 2005. Variabilidade temporal das condições climáticas sobre as perdas de $\mathrm{CO} 2$ na encosta do açude Namorados, em São João do Cariri-PB. MSc Thesis, Universidade Federal da Paraíba, Brazil.

Alafouzos, V., A. Vougiouka, Y. Perivolaris, D. Mourikis and V. Zagorakis et al., 2006. A method for estimating wind speed profile in complex terrain based on an advanced CFD tool. Proceedings of the EWEC Conference, (EWEC' 06), Athens, Greece.

Bañuelos-Ruedas, F., C. Angeles-Camacho and S. Rios-Marcuello, 2010. Analysis and validation of the methodology used in the extrapolation of wind speed data at different heights. Renewable Sustainable Energy Rev., 14: 2383-2391.

DOI: $10.1016 /$ j.rser.2010.05.001

Boute, A., 2012. Promoting renewable energy through capacity markets: An analysis of the Russian support scheme. Energy Policy, 46: 68-77.

DOI: 10.1016/j.enpol.2012.03.026
Bunse, U. and H. Mellinghoff, 2008. Influences of vertical wind profiles on power performance measurements. Proceedings of the 9th Deutsche WindenergieKonferenz, Nov. 27-28, Bremen, Germany.

Carvalho, D., A. Rocha, M. Gómez-Gesteira and C. Santos, 2012. A sensitivity study of the WRF model in wind simulation for an area of high wind energy. Environ. Modell. Software 33: 23-34. DOI: $10.1016 /$ j.envsoft.2012.01.019

Foken, T., 2006. Fifty years of the Monin-Obukhov similarity theory. Boundary-Layer Meteorol., 119: 431-447. DOI: 10.1007/s10546-006-9048-6

Golder, D., 1972. Relations among stability parameters in the surface layer. Boundary-Layer Meteorol., 3: 47-58. DOI: 10.1007/BF00769106

INMET, 2016. Normais Climatológicas do Brasil. Instituto Nacional de Meteorologia.

Martins, F.R. and E.B. Pereira, 2011. Enhancing information for solar and wind energy technology deployment in Brazil. Energy Policy, 39: 4378-4390. DOI: 10.1016/j.enpol.2011.04.058

Mcnaughton, K., 2009. The rise and fall of MoninObukhov Theory. AsiaFlux Newsletter.

Monin, A.S. and A.M. Obukhov, 1954. Basic laws of turbulent mixing in the ground layer of the atmosphere. Trudy Geofiz, Inst., 24: 163-187.

Pahlow, M., M.B. Parlange and F. Porté-Agel, 2001. On monin-obukhov similarity in the stable atmospheric boundary layer. Boundary-Layer Meteorol., 99: 225-248. DOI: 10.1023/A:1018909000098

Pereira, M.G., C.F. Camacho, M.A.V. Freitas and N.F. Da Silva, 2012. The renewable energy market in Brazil: Current status and potential. Renewable Sustainable Energy Rev., 16: 3786-3802. DOI: 10.1016/j.rser.2012.03.024

Sharan, M. and P. Kumar, 2010. Estimation of upper bounds for the applicability of non-linear similarity functions for non-dimensional wind and temperature profiles in the surface layer in very stable conditions. Proc. R Society A: Math. Phys. Eng. Sci., 467: 473-494. DOI: 10.1098/rspa.2010.0220

Stathopoulos, C., A. Kaperoni, G. Galanis and G. Kallos, 2013. Wind power prediction based on numerical and statistical models. J. Wind Eng. Industrial Aerodynam., 112: 25-38. DOI: 10.1016/j.jweia.2012.09.004

Stull, R.B., 1988. An Introduction to Boundary Layer Meteorology. 1st Edn., Springer Science and Business Media, Dordrecht, ISBN-10: 9027727694, pp: 670.

Wang, X., P. Guo and X. Huang, 2011. A review of wind power forecasting models. Energy Proc., 12: 770-778. DOI: 10.1016/j.egypro.2011.10.103 